\title{
Rapid quantification of mass transfer barriers in metal-organic framework crystals
}

Florencia A. Son, ${ }^{a \ddagger}$ Brandon C. Bukowski, ${ }^{b \ddagger, \dagger}$ Timur Islamoglu, ${ }^{\mathrm{a}}$ Randall Q. Snurr*b and Omar K. Farha.*a,b

a. Department of Chemistry and International Institute of Nanotechnology, Northwestern University, Evanston, Illinois 60208, United States

b. Department of Chemical and Biological Engineering, Northwestern University, Evanston, Illinois 60208, United States

Table of Contents

I. Instrumentation

II. Mathematical basis

III. MOF syntheses

IV. MOF characterization

V. 3Flex vapor isotherm setup

S8-S12

VI. $n$-Hexane isotherms

$\mathrm{S} 13$

VII. Mass transfer fittings

$\mathrm{S} 14-\mathrm{S} 22$

VIII. References 


\section{Instrumentation}

Sample Activation: Prior to $\mathrm{N}_{2}$ isotherms and $n$-hexane measurements, NU-1000 and MOF-808 were thermally activated under dynamic vacuum at $120{ }^{\circ} \mathrm{C}$ and UiO-66 was activated at $100{ }^{\circ} \mathrm{C}$ until outgas rates of $\leq 0.02$ Torr/s were achieved using a Micromeritics Smart VacPrep.

Nitrogen Physisorption Measurements: $\mathrm{N}_{2}$ isotherms were collected at $77 \mathrm{~K}$ using a Micromeritics ASAP2420. Pore size distribution analysis was performed using DFT calculations with a carbon slit geometry and a $\mathrm{N}_{2}$ DFT model.

Powder X-ray Diffraction (PXRD): PXRD measurements were collected on a STOE STADI P with a CuK $\alpha 1$ radiation source $(\lambda=1.54056 \AA)$ at the IMSERC X-ray Facility at Northwestern University

Scanning Electron Microscopy (SEM): SEM images were obtained using a FEI Quanta 650 at the EPIC facility (NUANCE Center-Northwestern University). The samples were coated with $9 \mathrm{~nm}$ of osmium using an SPF Osmium Coater (NUANCE Center-Northwestern University) prior to imaging.

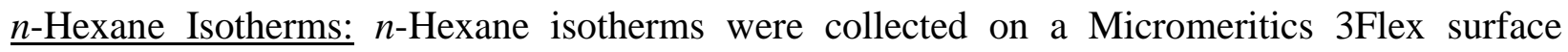
analyzer fitted with a vapor source container. Samples were maintained at $25{ }^{\circ} \mathrm{C}$ using a Micromeritics ISO Controller Temperature Control Device. Prior to using the $n$-hexane (99+\%, Acros Organics), the probe was degassed through a series of freeze-pump-thaw cycles on the instrument. 


\section{Mathematical basis}

The summarized details here are described in detail by Brandani. ${ }^{1,2}$ We first consider a mass balance for the dosing cell, valve assembly, and uptake cell. The mass balance on the valve assembly is:

$$
\frac{d n}{d t} \cong \bar{\chi}\left(P_{d}-P_{u}\right)
$$

Where $n$ is the number of moles, $\bar{\chi}$ is the valve coefficient, $P_{d}$ is the dosing pressure and $P_{u}$ is the uptake pressure. This holds in the limit of small pressure changes.

The mass balance on the uptake volume includes the free volume of the uptake cell $\epsilon V_{u}$ and volume of the solid $V_{s}$.

$$
V_{s} \frac{d \bar{q}}{d t}+\epsilon V_{u} \frac{d c}{d t}=\frac{d n}{d t}
$$

The mass balance of the dosing cell includes the dosing cell volume $V_{d}$, the dosing cell temperature $T_{d}$, and assume an ideal gas $R_{I G}$.

$$
\frac{d n}{d t}=-\frac{V_{d}}{R_{I G} T_{d}} \frac{d P_{d}}{d t}
$$

We can make draw a mass balance around the solid assuming a spherical particle according to Fickian diffusion where $q$ is the adsorbed phase.

$$
\frac{d q}{d t}=D\left(\frac{\partial^{2} q}{\partial r^{2}}+\frac{2}{r} \frac{\partial q}{\partial r}\right)
$$

And

$$
\frac{d \bar{q}}{d t}=\frac{3 D}{R}\left(\frac{\partial q}{\partial r}\right)_{r=R}+\frac{3}{R} k_{L D F}\left(q^{*}-\bar{q}\right)
$$

Where the first term on the right-hand side corresponds to intracrystalline diffusion and the second term on the right-hand side corresponds to a linear driving force. We assume that the adsorbed and gas phases are in equilibrium and invoke spherical symmetry in the particles.

The key assumptions used, which are explained in depth in Brandani's work, ${ }^{1,2}$ are:

1) The system is isothermal.

2) The system is linear.

3) There are no external or bed mass transfer resistances. 


\section{MOF Syntheses}

All MOF syntheses (NU-1000, ${ }^{3}$ MOF- $808,{ }^{4}$ and UiO- $66^{5}$ ) were made according to previously published procedures.

NU-1000: In a 5-L glass bottle, $\mathrm{ZrOCl}_{2} \cdot 8 \mathrm{H}_{2} \mathrm{O}(19.4 \mathrm{~g}, 60 \mathrm{mmol})$ and benzoic acid $(400 \mathrm{~g}, 3.2 \mathrm{~mol})$ were added to $1.2 \mathrm{~L}$ of $N, N$-dimethylformamide (DMF) and sonicated until dissolved. 4,4',4" $4^{\prime \prime \prime}$ (pyrene-1,3,6,8-tetrayl)tetrabenzoic acid (H4TBAPy) $(8 \mathrm{~g}, 12 \mathrm{mmol}$ ) was added to $400 \mathrm{~mL}$ of DMF in a $1 \mathrm{~L}$ glass bottle. Both solutions were placed in a $100{ }^{\circ} \mathrm{C}$ oven for 1 hour. After cooling to room temperature, the $\mathrm{H}_{4} \mathrm{TBAPy}$ solution and $8 \mathrm{~mL}$ of trifluoroacetic acid were added to the $\mathrm{Zr}$-solution, sonicated for 10 minutes, then placed in a $120{ }^{\circ} \mathrm{C}$ oven for 18 hours. The yellow product was collected by centrifugation and washed three times with DMF. Following this, the MOF was placed in a 5-L glass bottle with $2.6 \mathrm{~L}$ of DMF and $100 \mathrm{~mL}$ of $8 \mathrm{M} \mathrm{HCl}$ and heated in a $100{ }^{\circ} \mathrm{C}$ oven for 18 hours. The acid-washed MOF was collected by centrifugation and washed three times with DMF. The acid wash procedure was repeated once more and the final MOF was once again collected by centrifugations, washed three times with DMF, and three times with acetone, soaking for 1 hour in between washes. The MOF was placed in fresh acetone overnight, collected by centrifugation, and dried in an $80{ }^{\circ} \mathrm{C}$ vacuum oven for 1 hour. The NU-1000 was activated under dynamic vacuum at $120^{\circ} \mathrm{C}$ until the degas rates were below $0.02 \mathrm{Torr} / \mathrm{s}$.

MOF-808: In a $100 \mathrm{~mL}$ round-bottom flask, $\mathrm{ZrOCl}_{2} \cdot 8 \mathrm{H}_{2} \mathrm{O}(1.932 \mathrm{~g}, 6.0 \mathrm{mmol})$, trimesic acid (420 $\mathrm{mg}, 2.0 \mathrm{mmol})$, formic acid $(20 \mathrm{~mL})$, deionized water $(20 \mathrm{~mL})$, and $\mathrm{HCl}(12 \mathrm{M}, 200 \mu \mathrm{L})$ were added. The mixture was heated on an aluminum heating block at $110^{\circ} \mathrm{C}$ for 18 hours while stirring at $300 \mathrm{rpm}$. After, the MOF was collected by centrifugation, washed three times with water (soaking for 30 minutes after each wash), and placed into a clean $100 \mathrm{~mL}$ round-bottom flask with $40 \mathrm{~mL}$ of $1 \mathrm{M} \mathrm{HCl}$. This mixture was heated overnight on an aluminum heating block at $90{ }^{\circ} \mathrm{C}$. The MOF was collected by centrifugation, washed three times with water followed by three ethanol washes, soaking for 1 hour between each wash. After soaking the MOF in ethanol overnight, MOF- 808 was collected by centrifugation, dried in an $80{ }^{\circ} \mathrm{C}$ vacuum oven for 1 hour, and activated under dynamic vacuum at $120^{\circ} \mathrm{C}$ until the degas rates were below $0.02 \mathrm{Torr} / \mathrm{s}$.

UiO-66: In a 2-L glass bottle, terephthalic acid ( $0.9 \mathrm{~g}, 5.42 \mathrm{mmol}), 140 \mu \mathrm{L}$ triethylamine, 128.8 $\mathrm{mL}$ acetic acid, and $1.26 \mathrm{~L}$ of DMF were added and sonicated until dissolved. The solution was heated at $100{ }^{\circ} \mathrm{C}$ for 15 minutes and then allowed to cool completely. While heating the linker solution, $\mathrm{ZrCl}_{4}(1.26 \mathrm{~g}, 5.41 \mathrm{mmol})$ was sonicated in $90 \mathrm{~mL}$ of $\mathrm{DMF}$ until dissolved. The $\mathrm{Zr}$ solution was added to the linker solution and placed in a $100{ }^{\circ} \mathrm{C}$ oven for 18 hours. Majority of the supernatant was first decanted before collecting the MOF by centrifugation. The MOF was washed with DMF and acetone three times, soaking 1 hour in between each wash. After soaking in fresh acetone overnight, UiO-66 was isolated by centrifugation, dried for 1 hour in an $80{ }^{\circ} \mathrm{C}$ vacuum oven, and activated under dynamic vacuum at $100{ }^{\circ} \mathrm{C}$ until degas rates of $<0.02 \mathrm{Torr} / \mathrm{s}$ were reached. 
IV. MOF Characterization

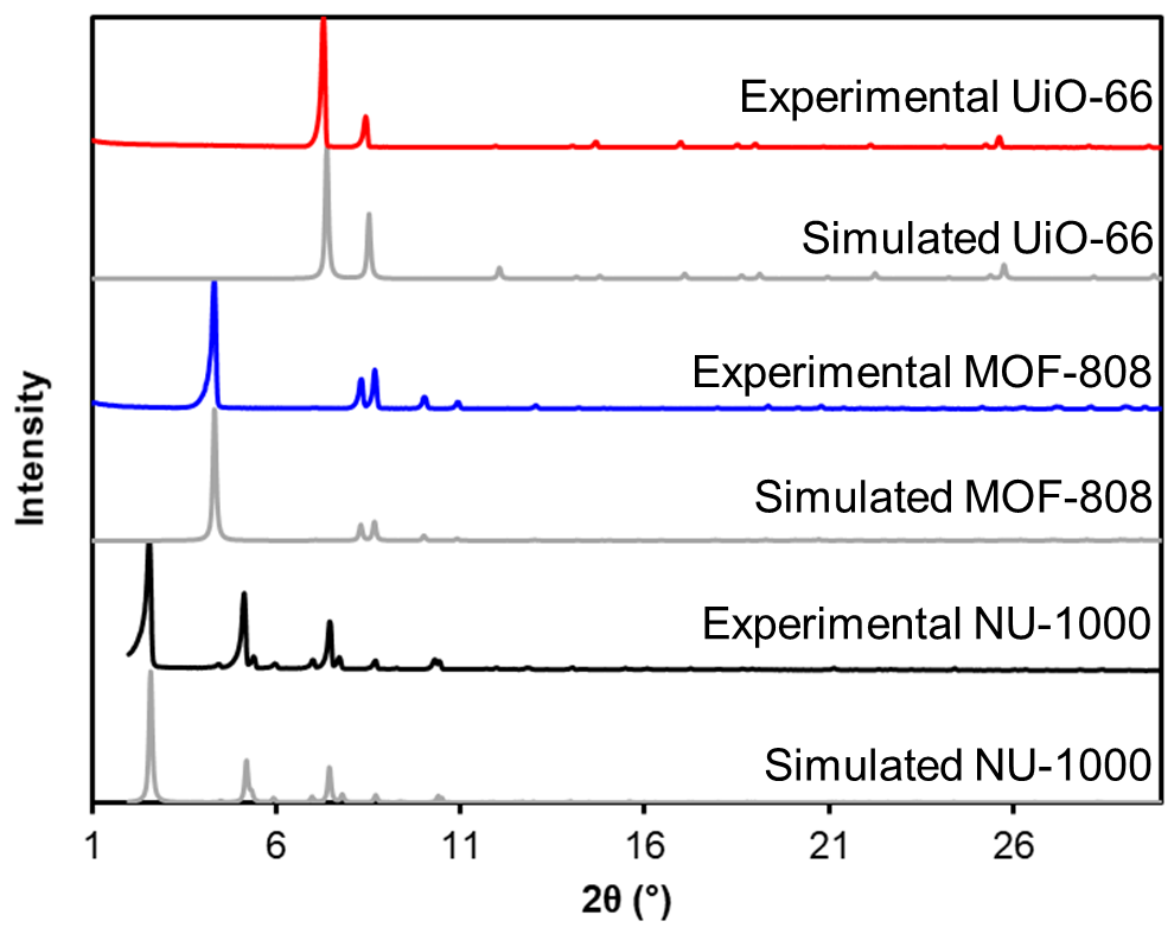

Figure S1. Simulated and experimental PXRD patterns of NU-1000, MOF-808, and UiO-66. 

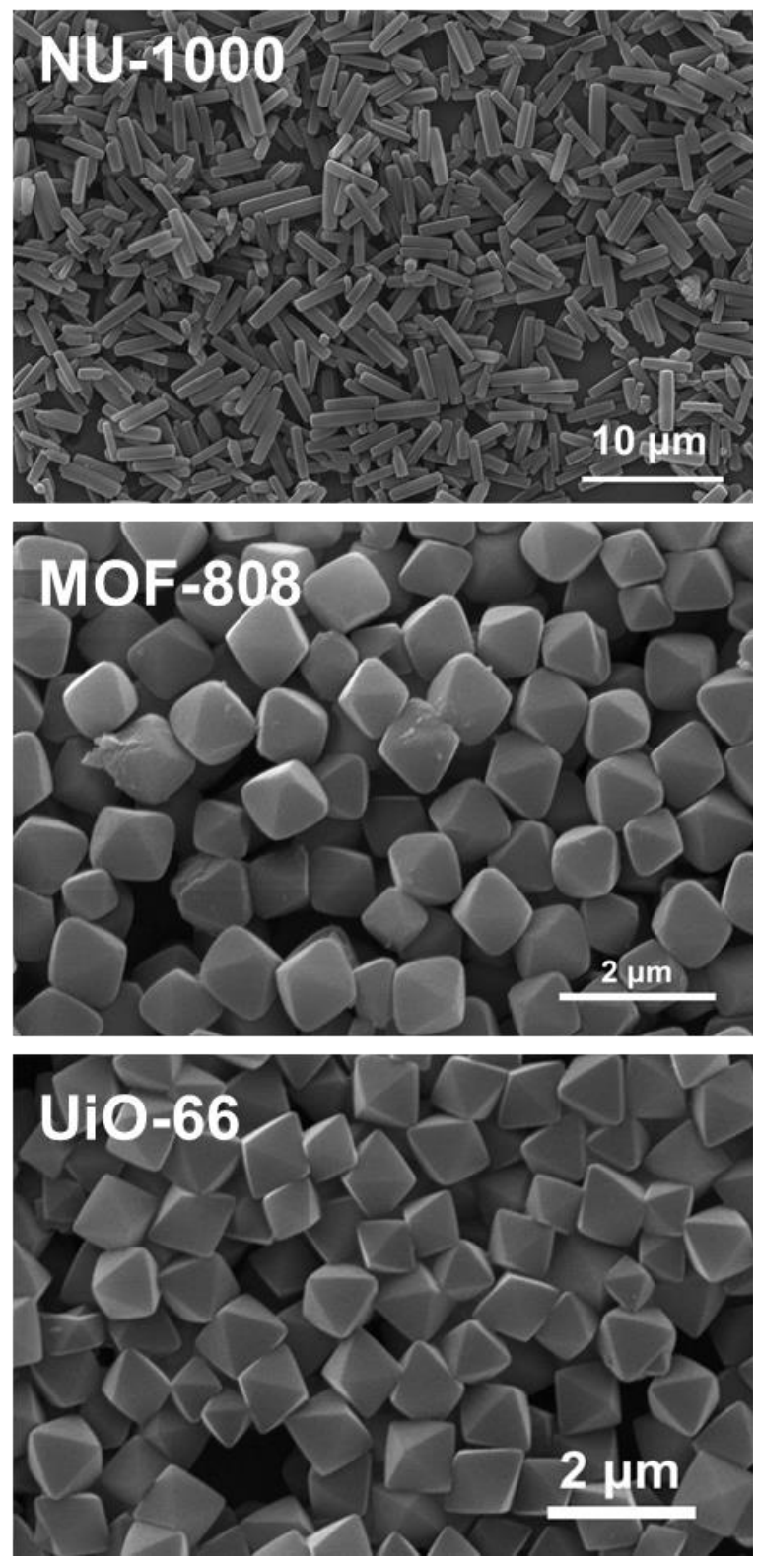

Figure S2. SEM of NU-1000 (average length $=4 \mu \mathrm{m}$, particle radius is $2 \mu \mathrm{m}$ ), MOF- 808 (average length $=1 \mu \mathrm{m}$, particle radius is $0.5 \mu \mathrm{m}$ ), and UiO-66 (average length $=1 \mu \mathrm{m}$, particle radius is $0.5 \mu \mathrm{m}$ ). 
A

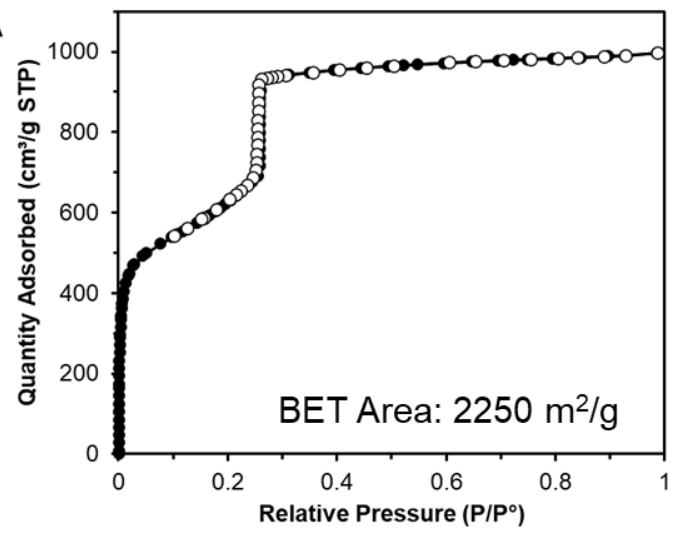

C

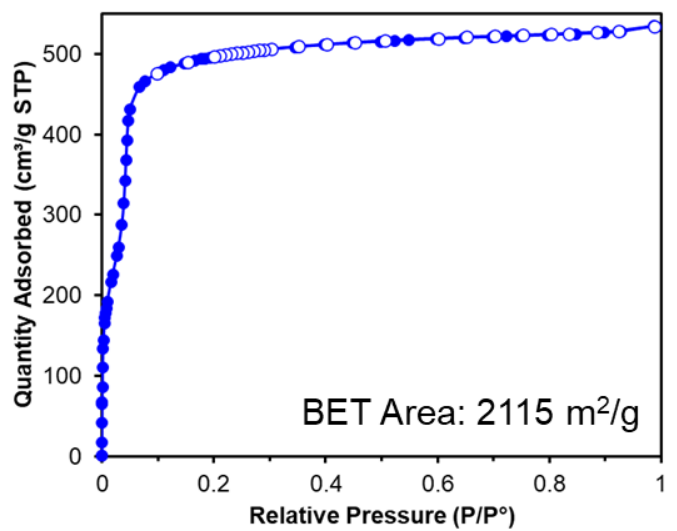

E

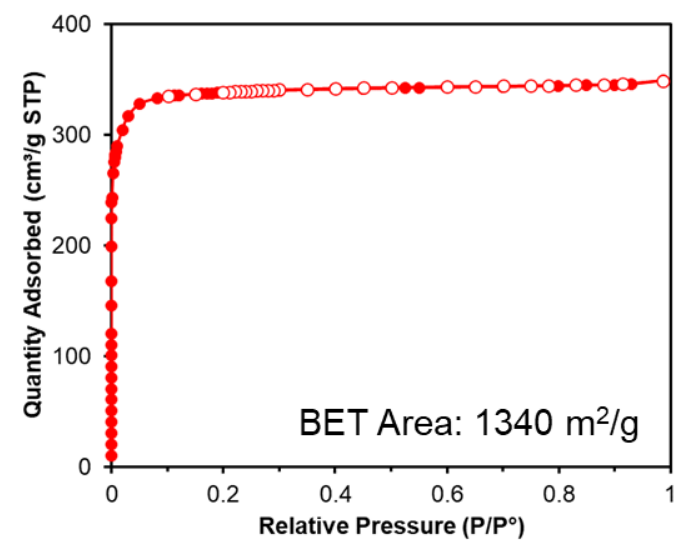

B

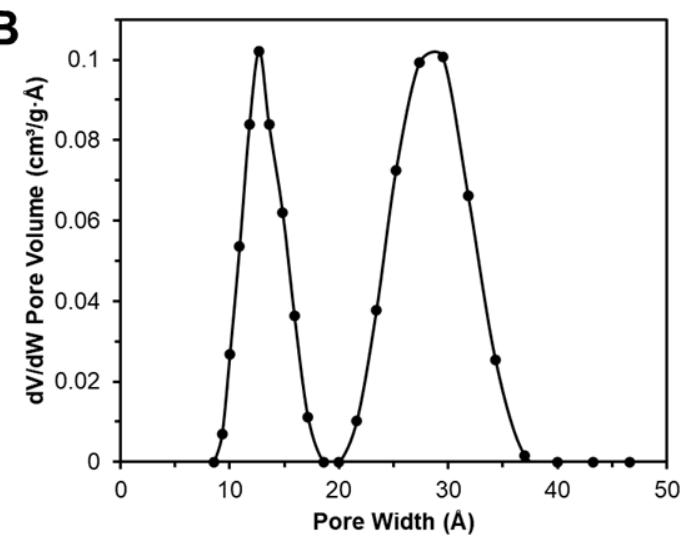

D

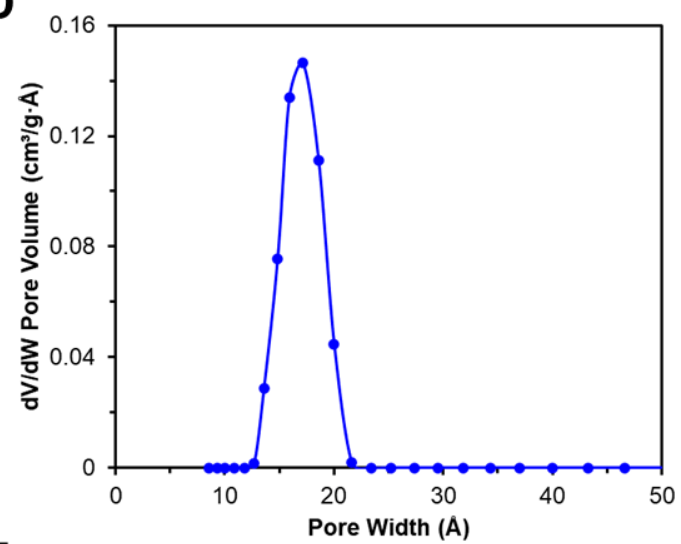

$\mathbf{F}$

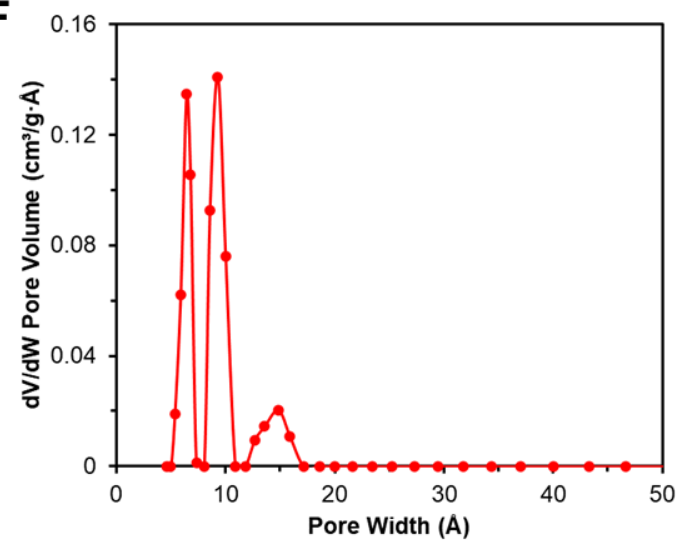

Figure S3. Nitrogen isotherms collected at $77 \mathrm{~K}$ with closed markers representing adsorption and open markers desorption for A) NU-1000, C) MOF-808, and E) UiO-66. Pore size distribution of B) NU-1000, D) MOF-808, and F) UiO-66. 


\section{3Flex Vapor Isotherm Setup}

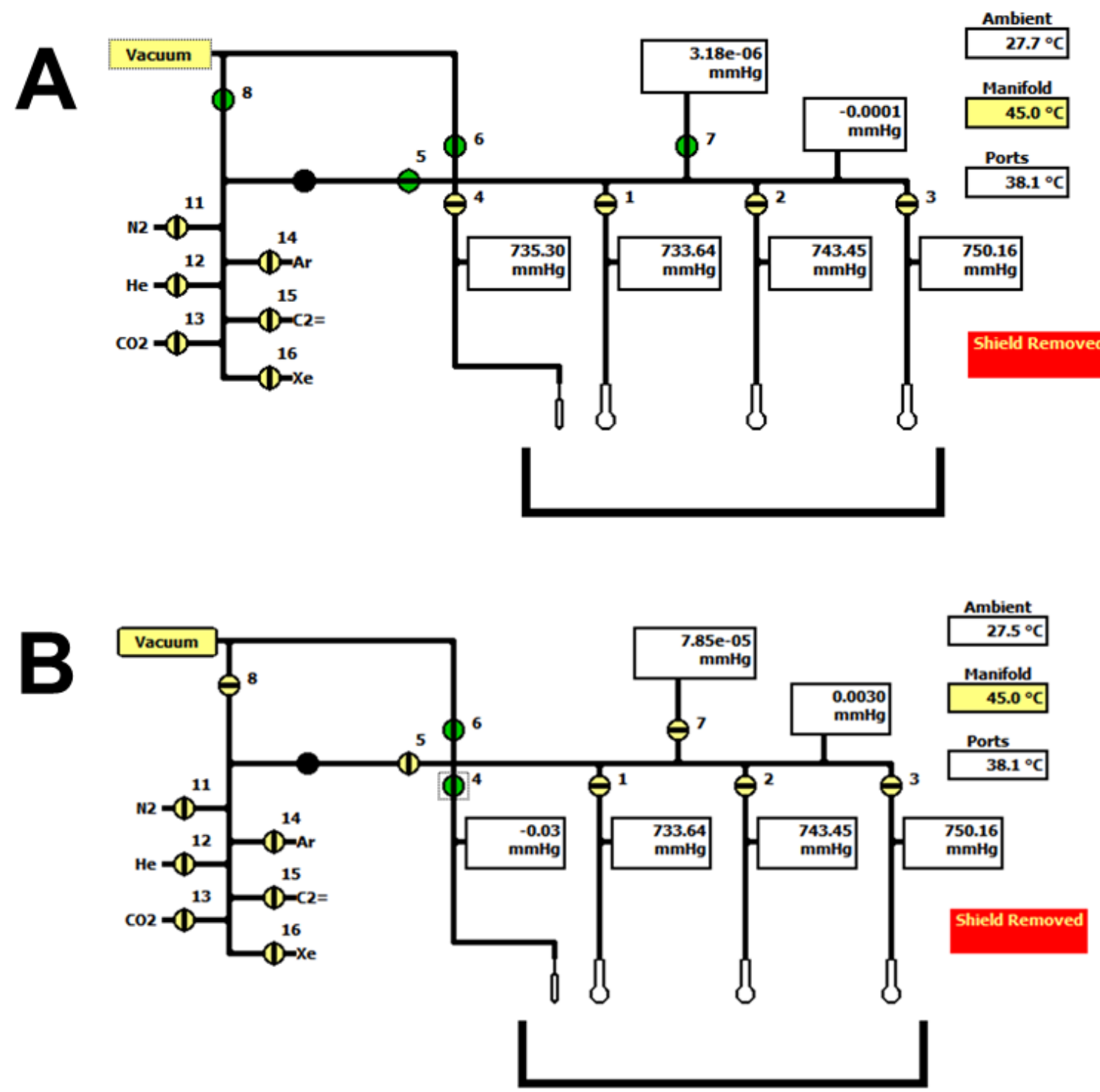




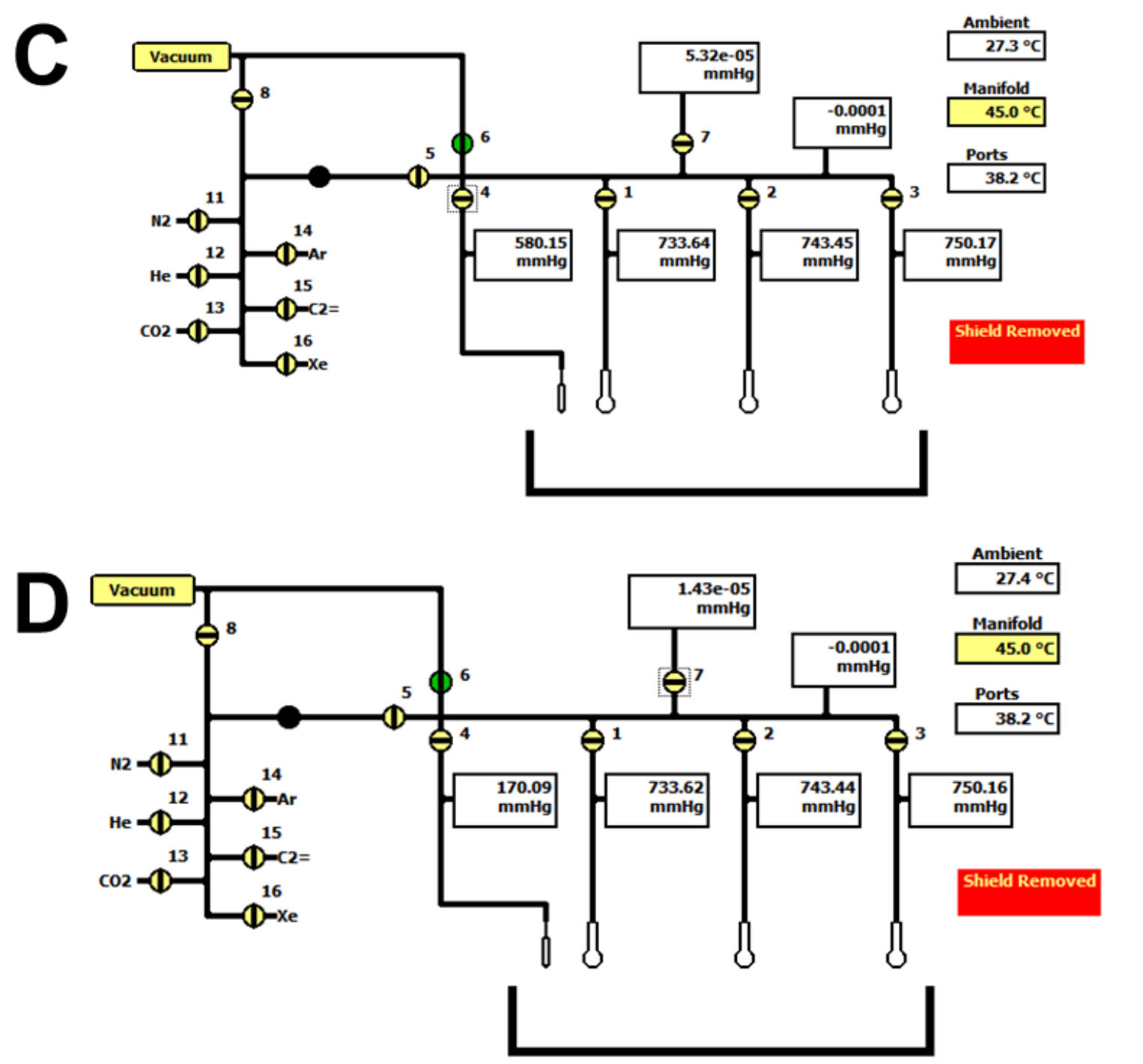



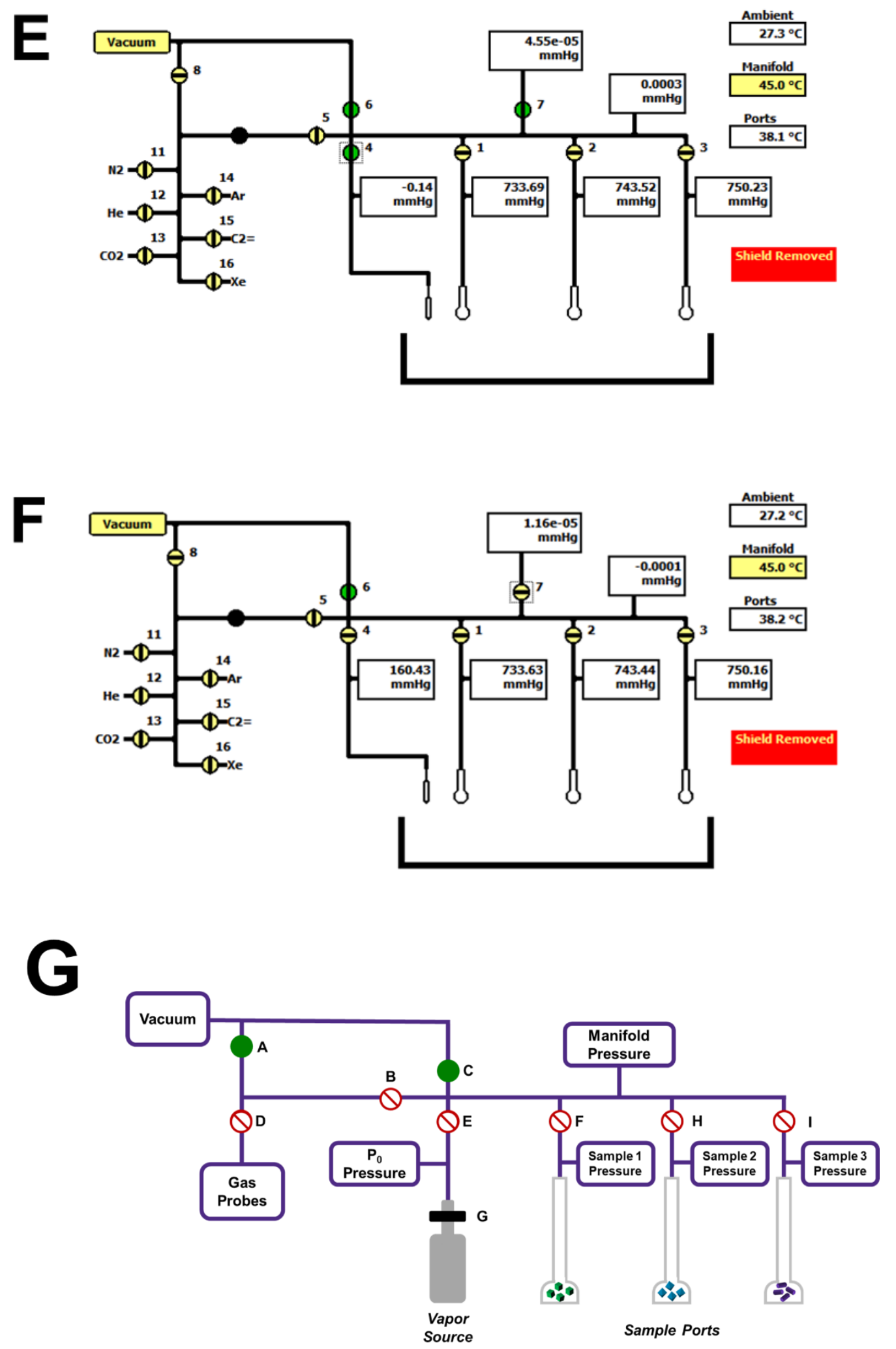

Figure S4. 3Flex instrument schematic for vapor purification (A-F) and a simplified cartoon depiction of the instrument schematic $(\mathrm{G})$. 
A) Schematic after vapor source installation with close-off valve on vapor source container closed.

B) With close-off valve on vapor source still closed, open valve 4 on the instrument to clear the headspace of the vapor reservoir.

C) Close valve 4, then open close-off valve of vapor source container.

D) Submerge vapor source container in liquid nitrogen until the pressure stabilizes. For the first freeze cycle, it will not reach zero. In this example, the pressure dropped until 170 Torr (reading from valve 4)

E) Once the pressure of the vapor container is stabilized, open valve 4 to expose the container to vacuum, while ensuring that the reservoir is still submerged in liquid nitrogen. Leave valve 4 open until pressures of $10^{-4}-10^{-5}$ Torr (reading from valve 7 ) are achieved.

F) Close valve 4 and submerge the vapor source container in water to thaw. If the pressure reading is not close to the calculated saturation pressure at room temperature, this is indicative of residual impurities. If impurities remain, repeat steps $\mathrm{B}$ through $\mathrm{F}$ for additional cycle(s).

G) Simplified depiction of instrument schematic
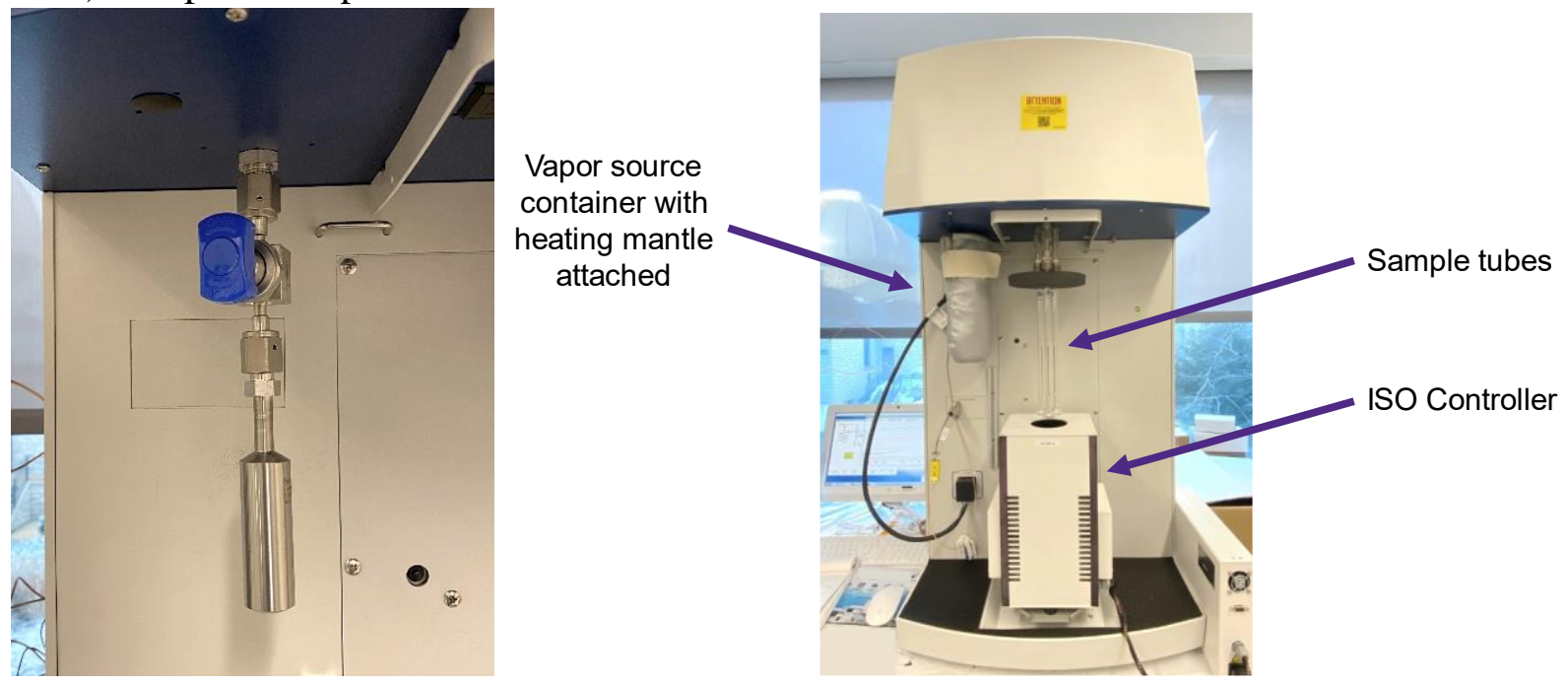

Figure S5. 3Flex setup. Left) installed vapor source container with the close-off valve open. Right) final vapor isotherm collection setup. 
Free Space Measurements: Free space, or void/dead space, measurements determine the empty volume in the sample tube, unoccupied by the sample. The quantity adsorbed of a probe ( $\left.\mathrm{n}_{\text {adsorbed }}\right)$ is calculated from the difference between the quantity dosed $\left(\mathrm{n}_{\text {dosed }}\right)$ and the quantity of the probe remaining in the gas/vapor phase in the sample tube ( $\mathrm{n}_{\text {residual }}$ ) (equation 6). The quantity dosed is determined by the change in pressure in the instrument manifold before and after the dose is delivered. $\mathrm{n}_{\text {residual }}$ is calculated using the free space volume. Other values used in these measurements include the manifold volume, or dosing volume $\left(\mathrm{V}_{\mathrm{D}}\right)$ and the sample volume $\left(\mathrm{V}_{\mathrm{S}}\right)$.

$$
n_{\text {adsorbed }}=n_{\text {dosed }}-n_{\text {residual }}
$$

The Micromeritics 3Flex analyzer can be programmed to automatically measure the free space prior to analysis. As these measurements are performed with the sample in the sample tubes, a gas such as helium, which does not adsorb into the material, is used. The free space is measured using gas laws under two temperatures since a temperature gradient may exist. First, it's measured under ambient conditions, which the top of the sample holder will be subjected to during analysis. Finally, it's measured at the analysis temperature, which the sample will experience. These two values are used to determine the void space more accurately at the analysis temperature using a compressibility correction. 


\section{VI. $n$-Hexane Isotherms}
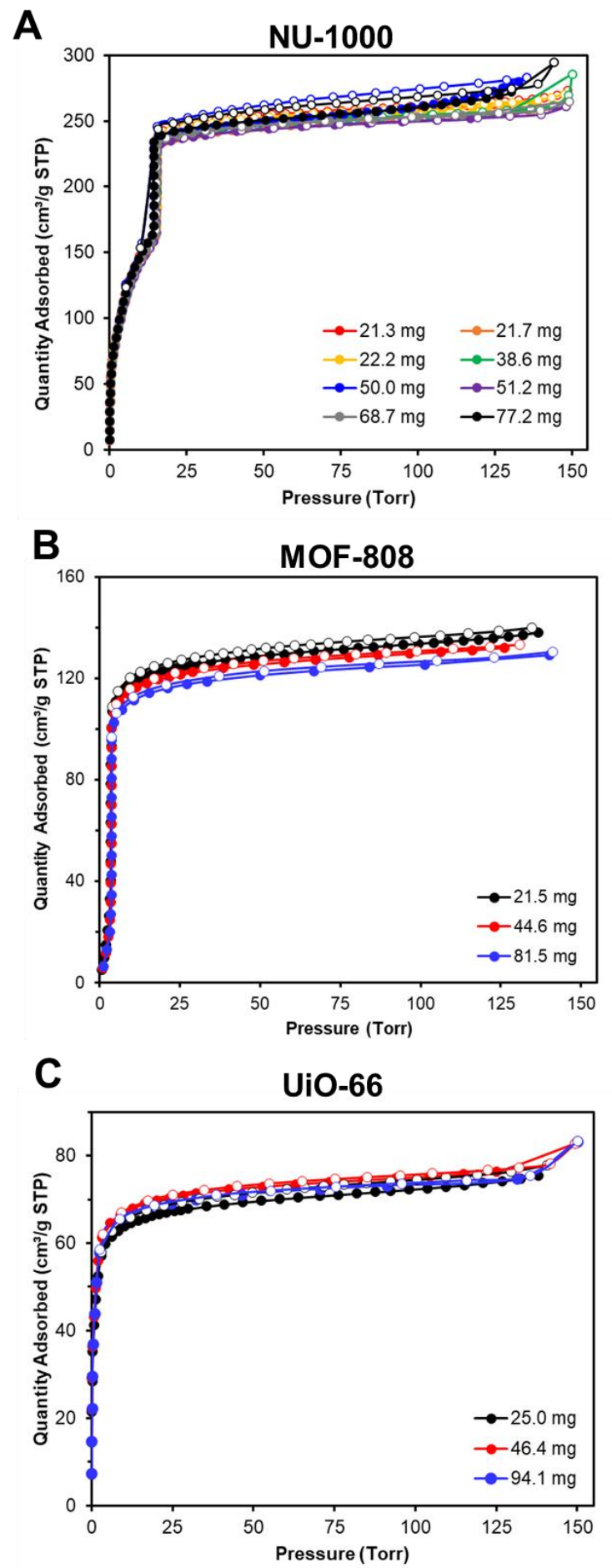

Figure S6. Overlayed $n$-hexane isotherms for A) NU-1000, B) MOF-808, and C) UiO-66 samples at $298 \mathrm{~K}$. Closed markers represent adsorption and open represent desorption. 


\section{Mass Transfer Fittings}
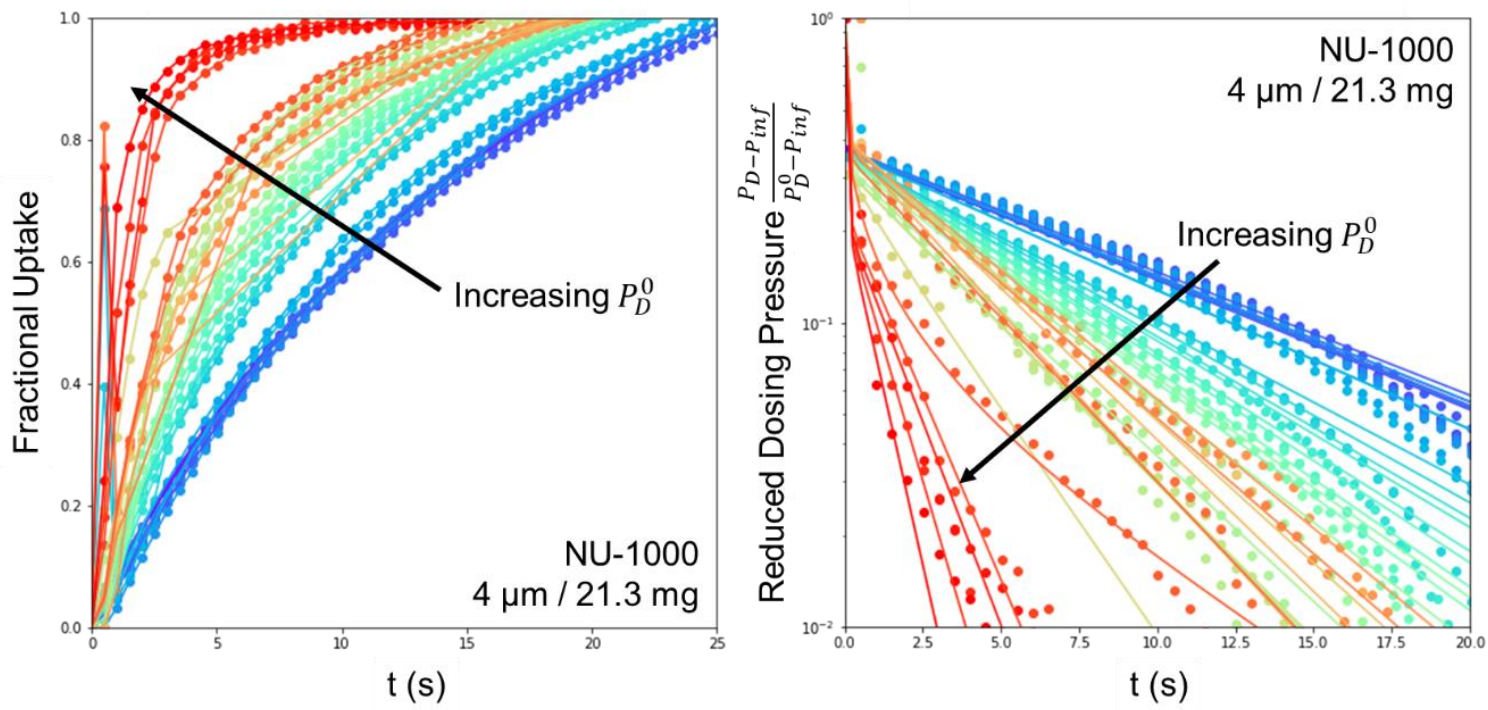

Figure S7. Left) Fractional uptake versus time of $n$-hexane in NU-1000 and their corresponding dosing pressures $(21.3 \mathrm{mg})$. Sharp jumps at early times, as seen in the light green trace,

correspond to instrument errors in the transient data collection. As illustrated by the reproducibility of these results, however, the precision of the results is not impacted by these fluctuations. Right) Reduced dosing pressures versus time.
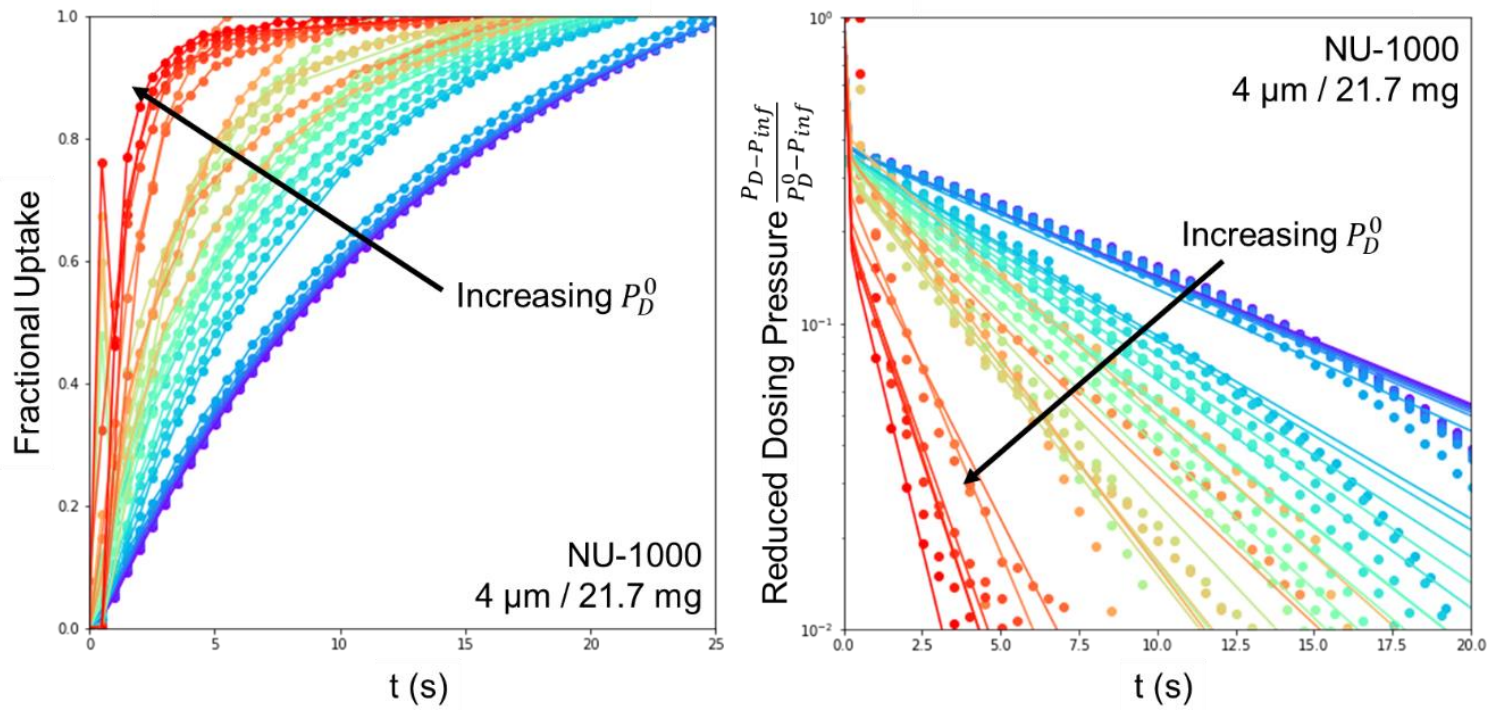

Figure S8. Left) Fractional uptake versus time of $n$-hexane in NU-1000 and their corresponding dosing pressures (21.7 mg). Right) Reduced dosing pressures versus time. 

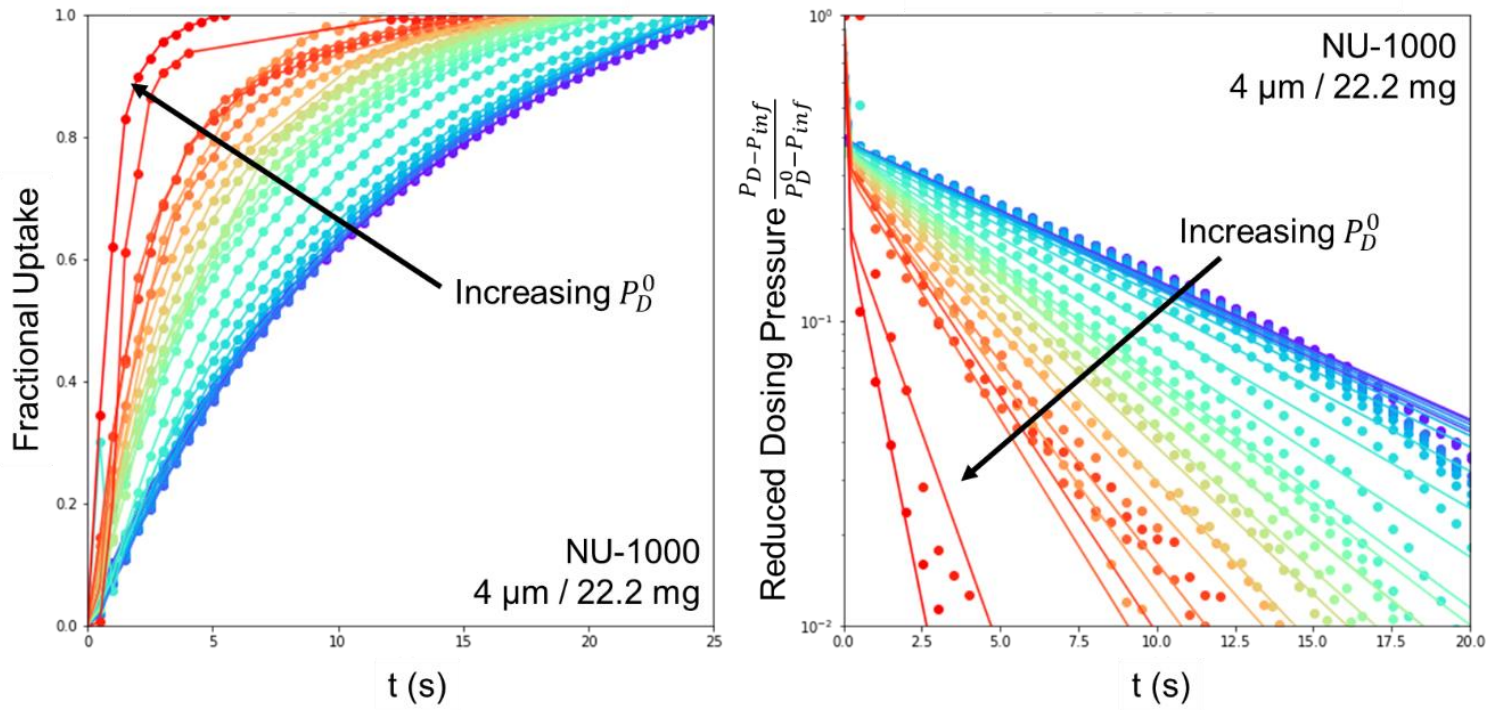

Figure S9. Left) Fractional uptake versus time of $n$-hexane in NU-1000 and their corresponding dosing pressures (22.2 mg). Right) Reduced dosing pressures versus time.
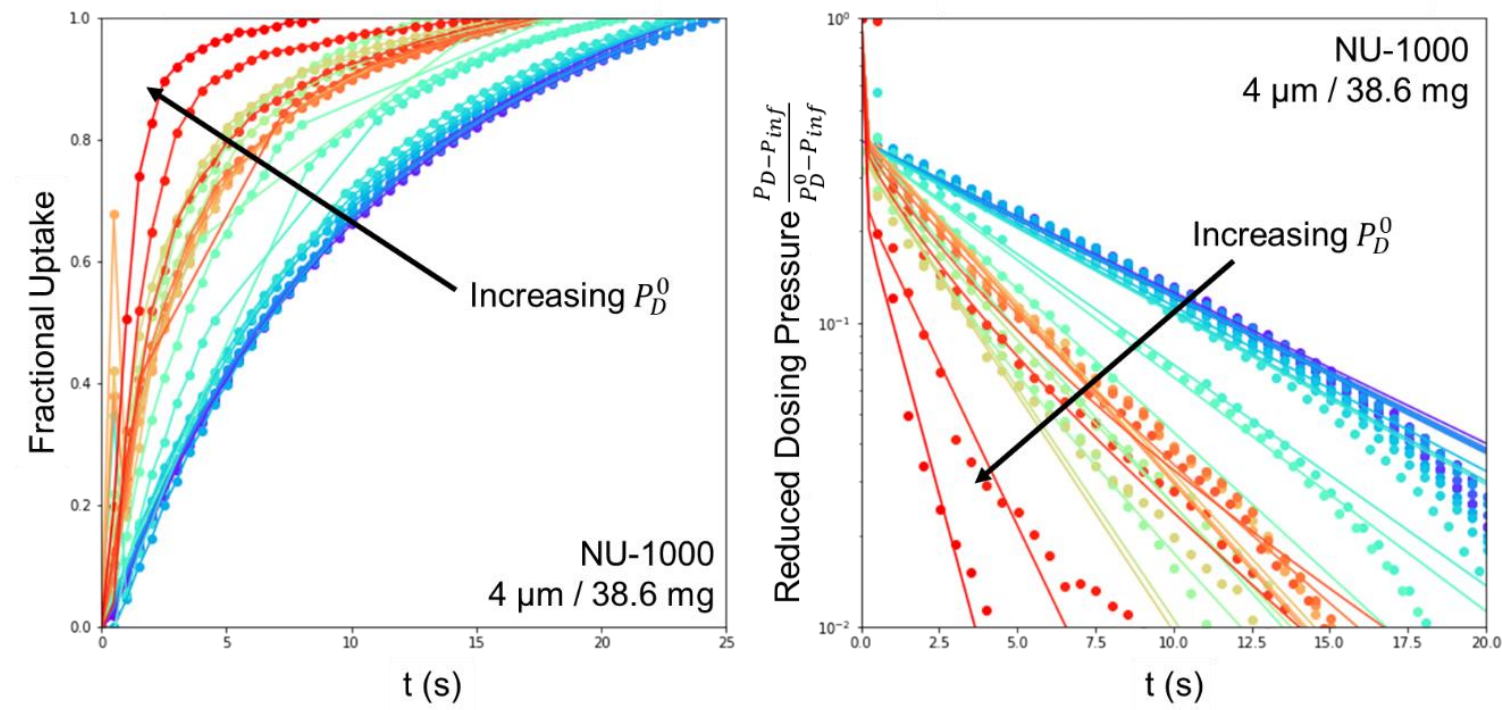

Figure S10. Left) Fractional uptake versus time of $n$-hexane in NU-1000 and their corresponding dosing pressures (38.6 mg). Right) Reduced dosing pressures versus time. 

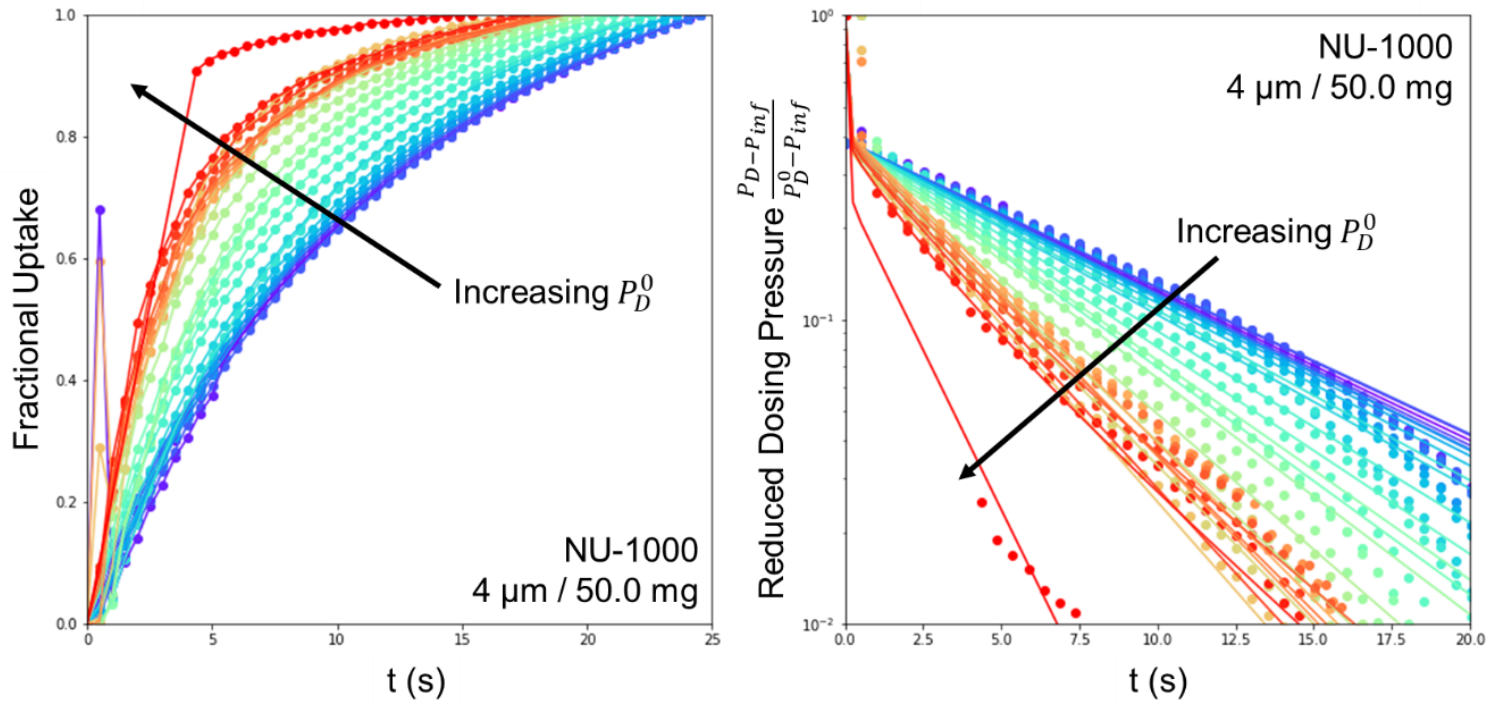

Figure S11. Left) Fractional uptake versus time of $n$-hexane in NU-1000 and their corresponding dosing pressures (50.0 mg). Right) Reduced dosing pressures versus time.
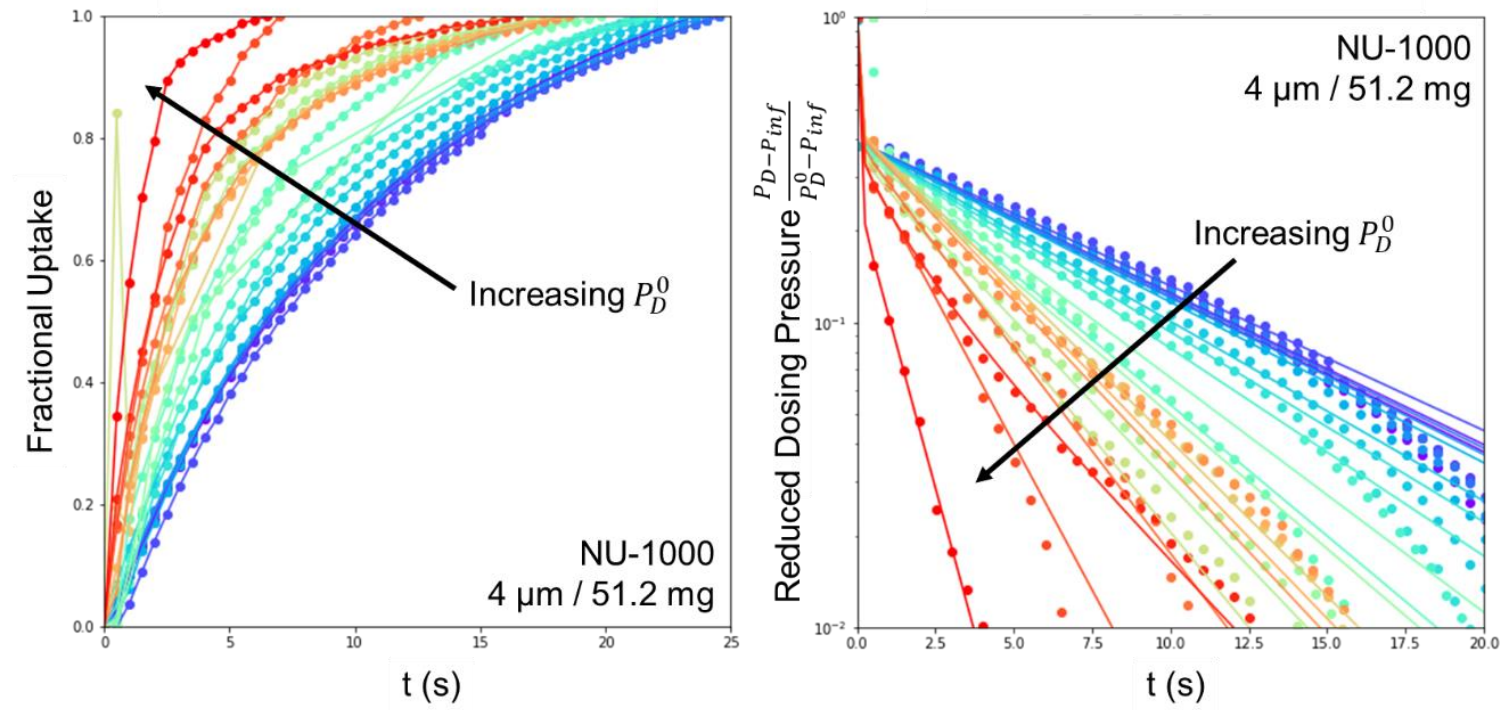

Figure S12. Left) Fractional uptake versus time of $n$-hexane in NU-1000 and their corresponding dosing pressures (51.2 mg). Right) Reduced dosing pressures versus time. 

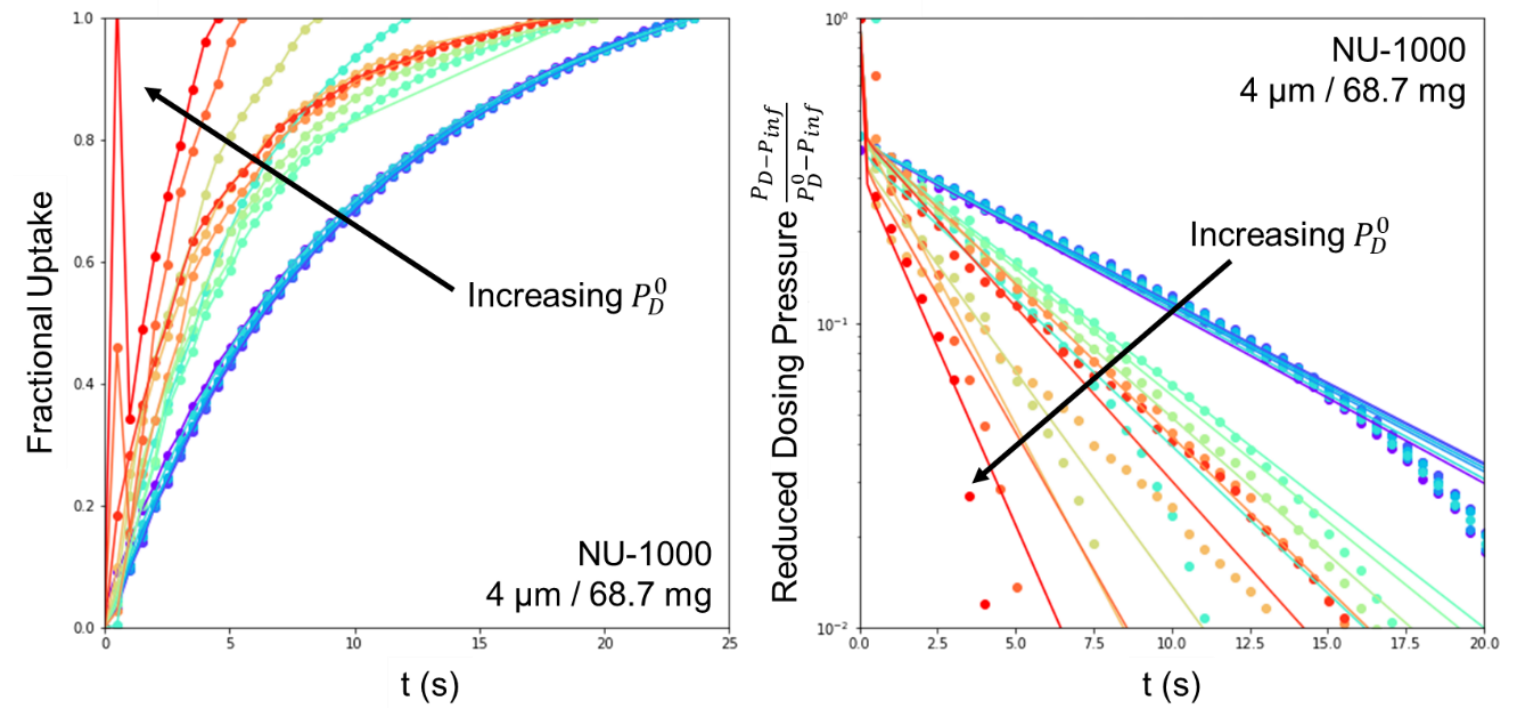

Figure S13. Left) Fractional uptake versus time of $n$-hexane in NU-1000 and their corresponding dosing pressures $(68.7 \mathrm{mg})$. Right) Reduced dosing pressures versus time.
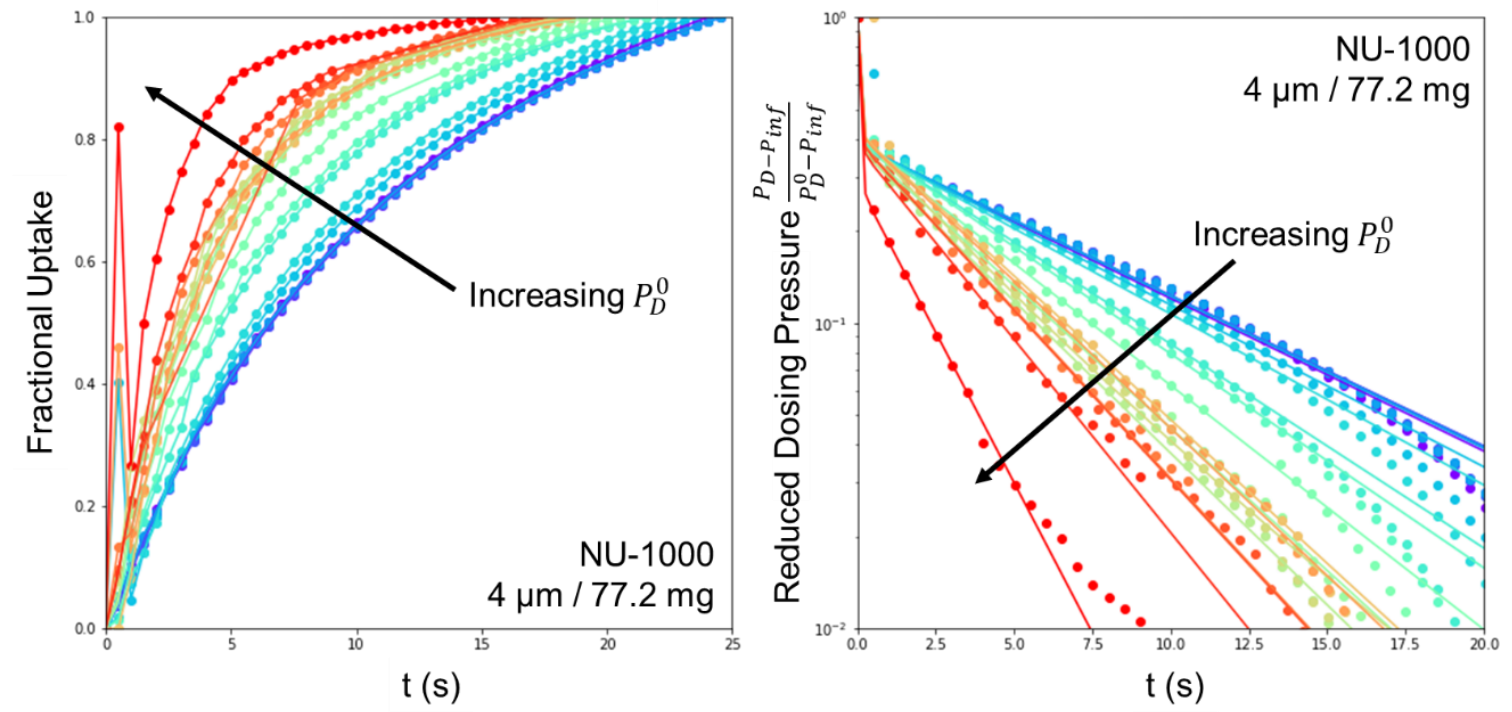

Figure S14. Left) Fractional uptake versus time of $n$-hexane in NU-1000 and their corresponding dosing pressures (77.2 mg). Right) Reduced dosing pressures versus time. 

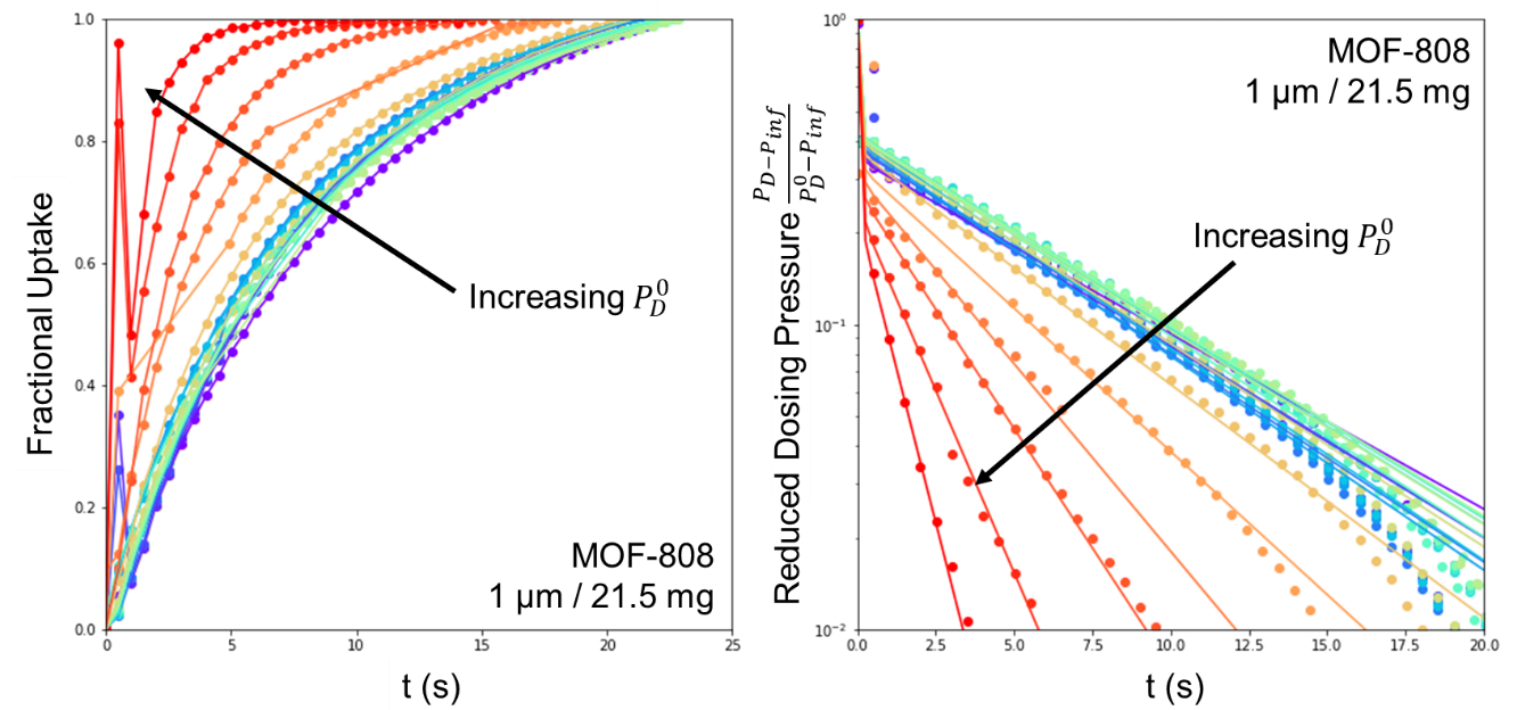

Figure S15. Left) Fractional uptake versus time of $n$-hexane in MOF-808 and their corresponding dosing pressures $(21.5 \mathrm{mg})$. Right) Reduced dosing pressures versus time.
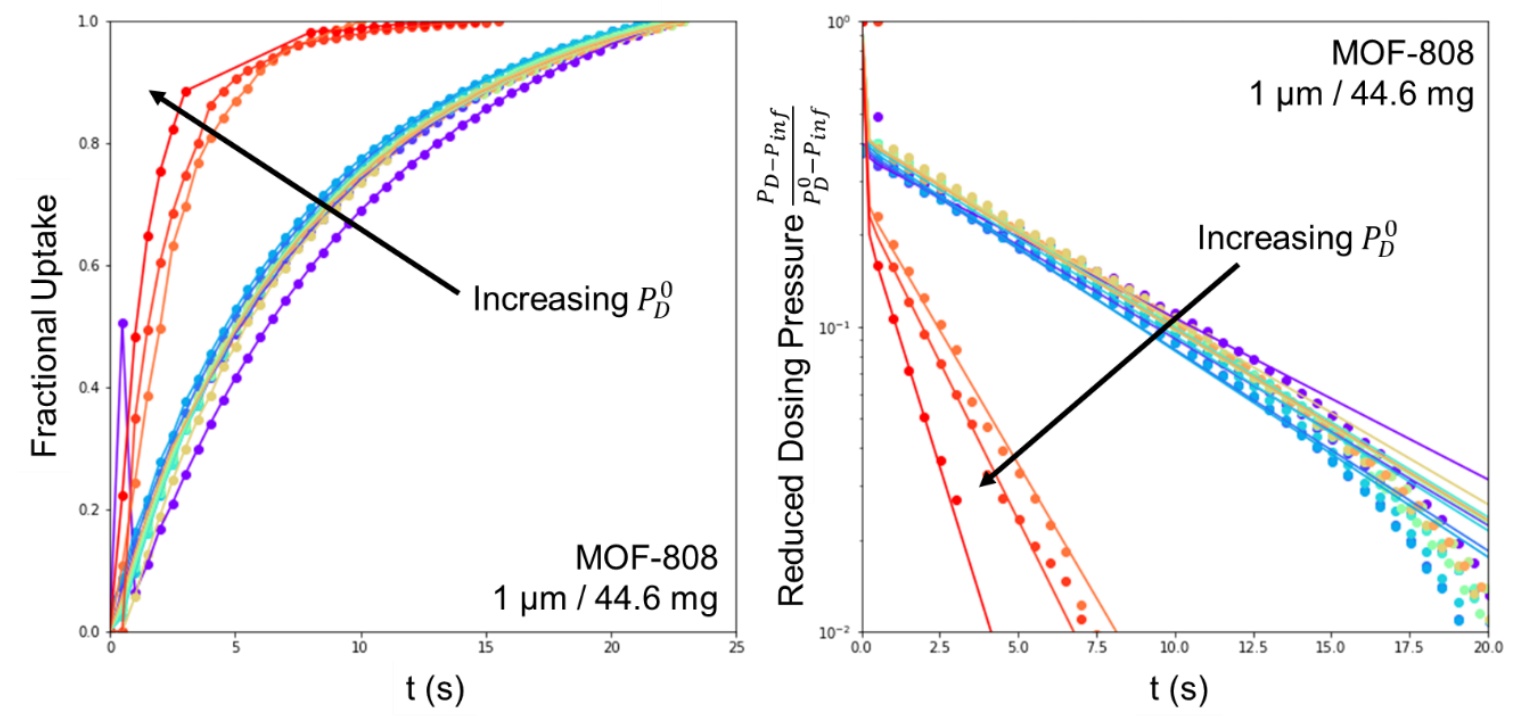

Figure S16. Left) Fractional uptake versus time of $n$-hexane in MOF-808 and their corresponding dosing pressures (44.6 mg). Right) Reduced dosing pressures versus time. 

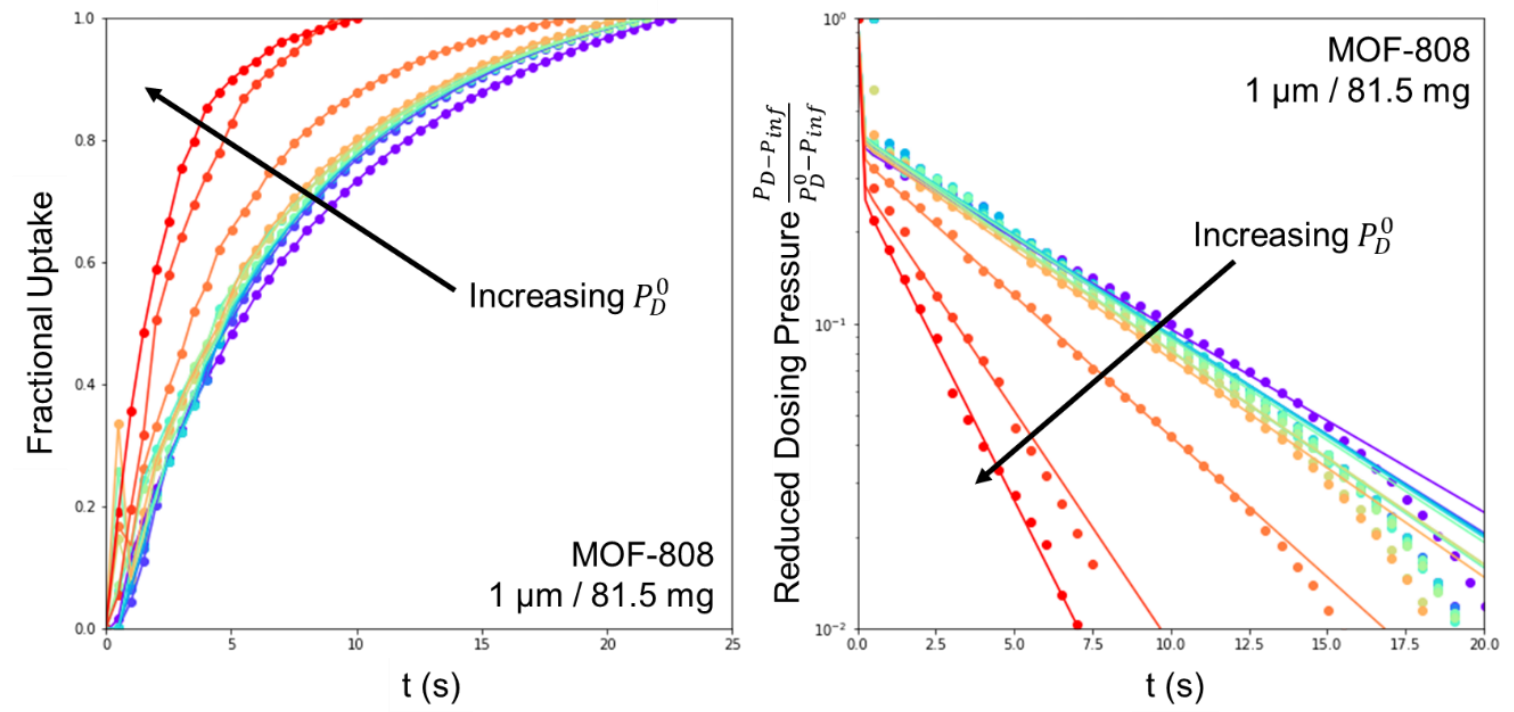

Figure S17. Left) Fractional uptake versus time of $n$-hexane in MOF-808 and their corresponding dosing pressures $(81.5 \mathrm{mg})$. Right) Reduced dosing pressures versus time.
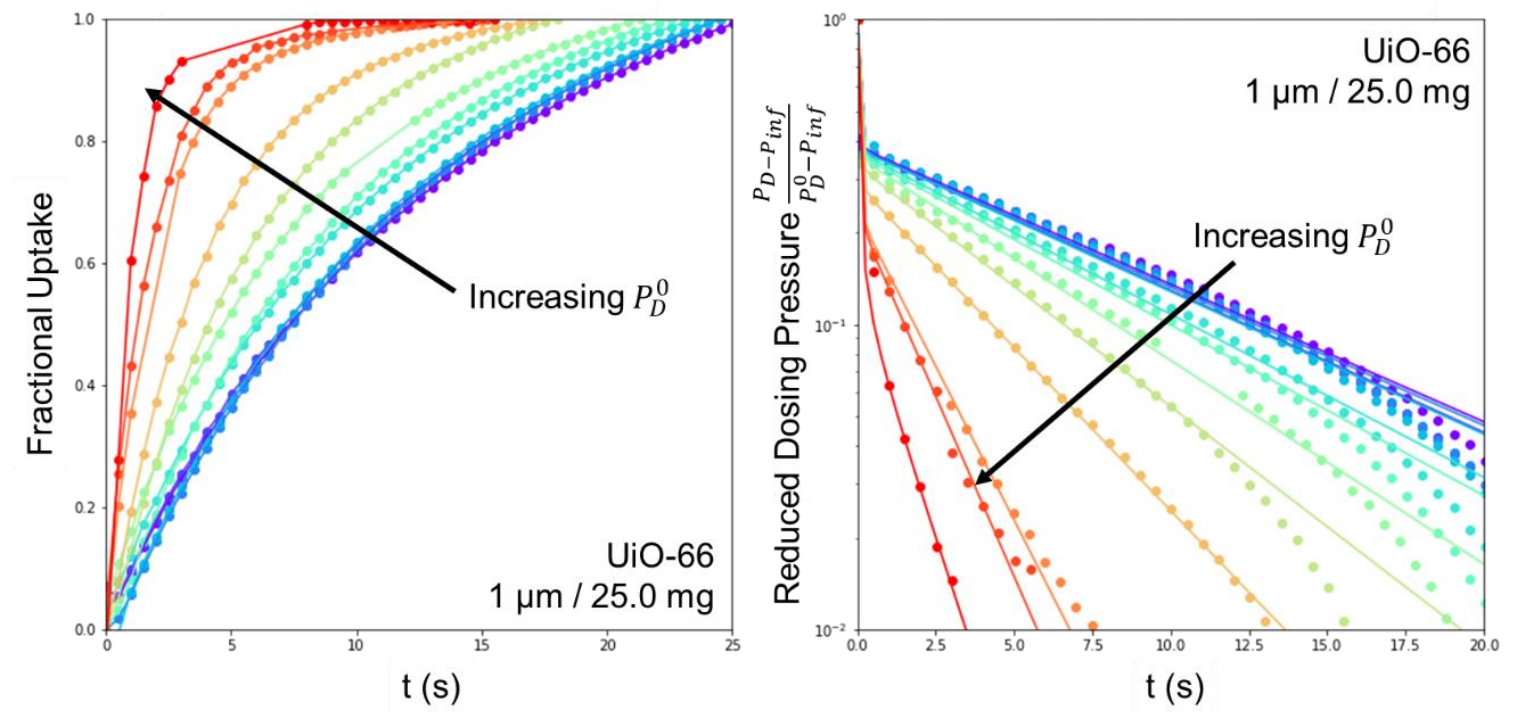

Figure S18. Left) Fractional uptake versus time of $n$-hexane in UiO-66 and their corresponding dosing pressures $(25.0 \mathrm{mg}$ ). Right) Reduced dosing pressures versus time. 

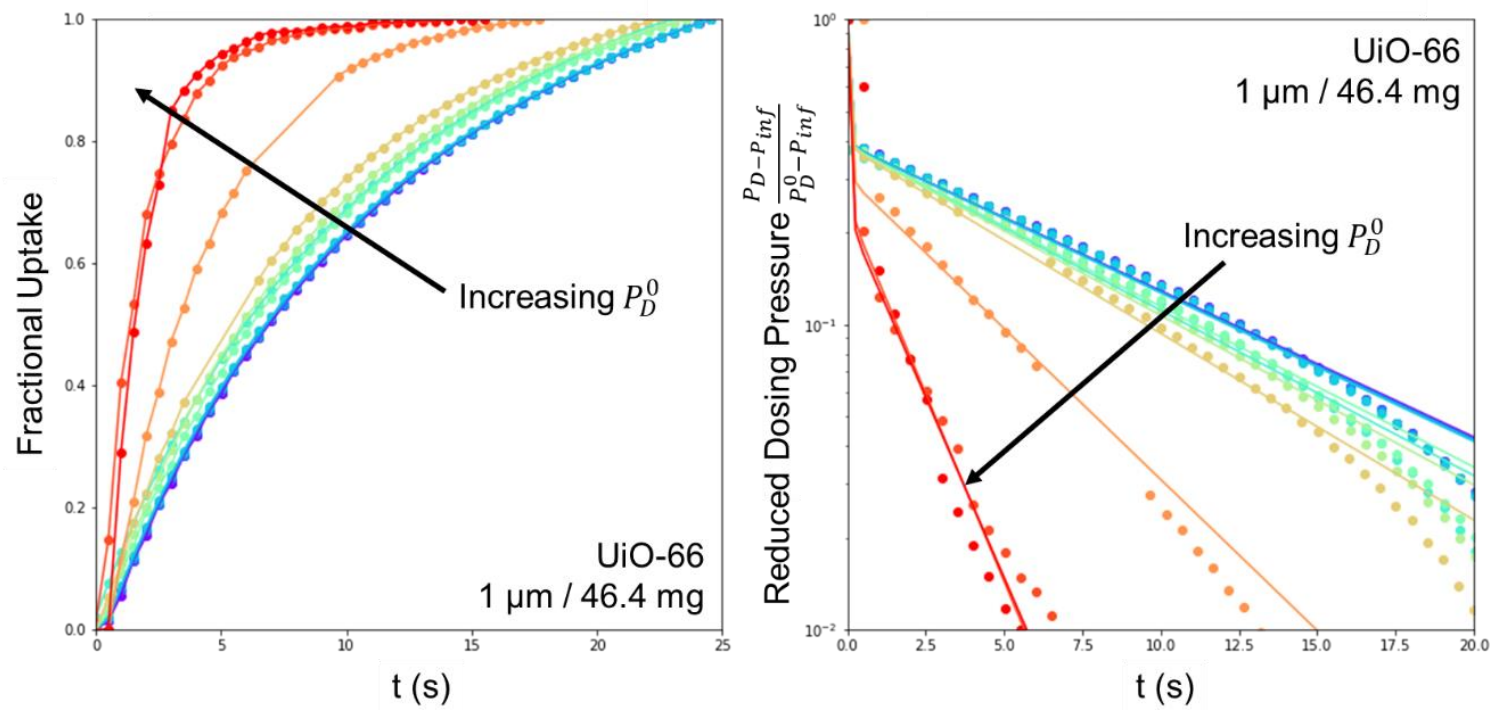

Figure S19. Left) Fractional uptake versus time of $n$-hexane in UiO-66 and their corresponding dosing pressures (46.4 mg). Right) Reduced dosing pressures versus time.
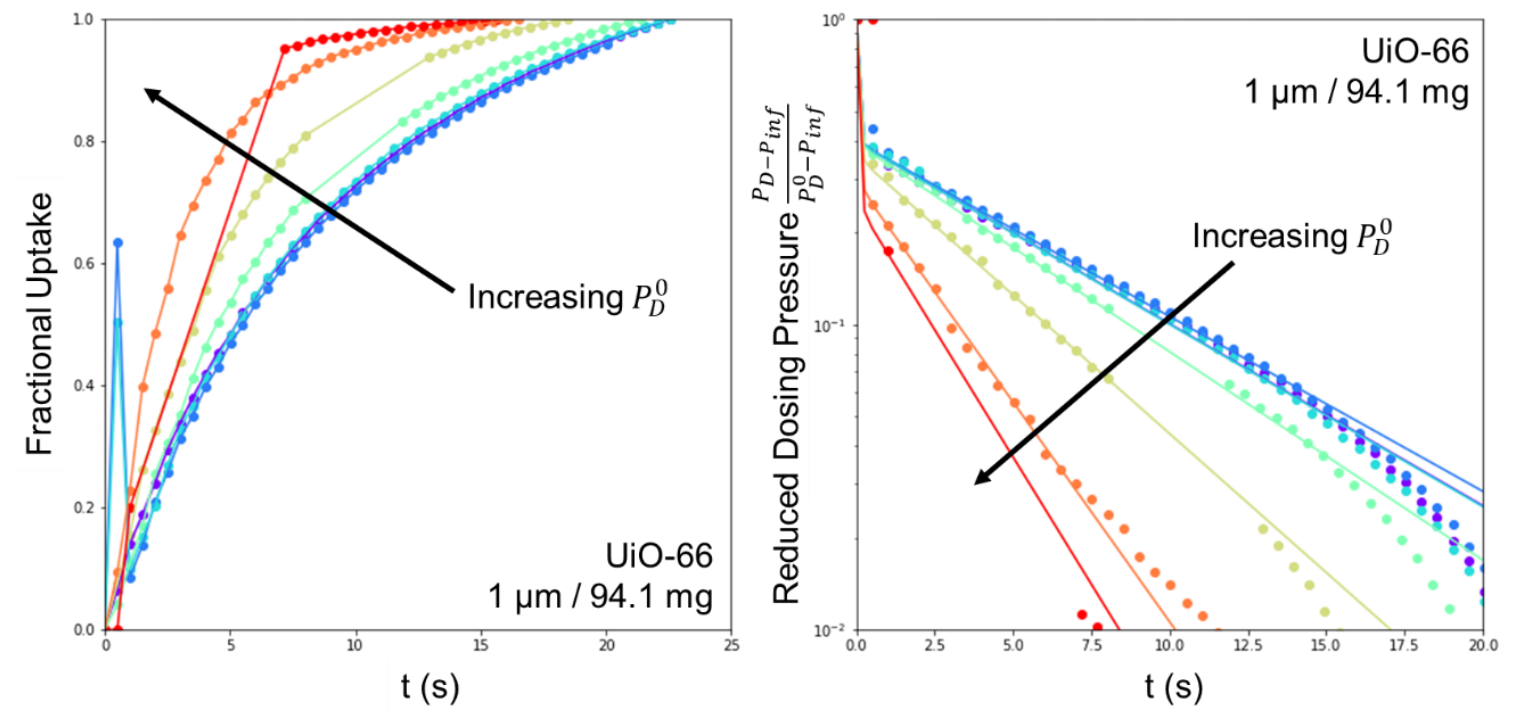

Figure S20. Left) Fractional uptake versus time of $n$-hexane in UiO-66 and their corresponding dosing pressures (94.1 mg). Right) Reduced dosing pressures versus time. 
A

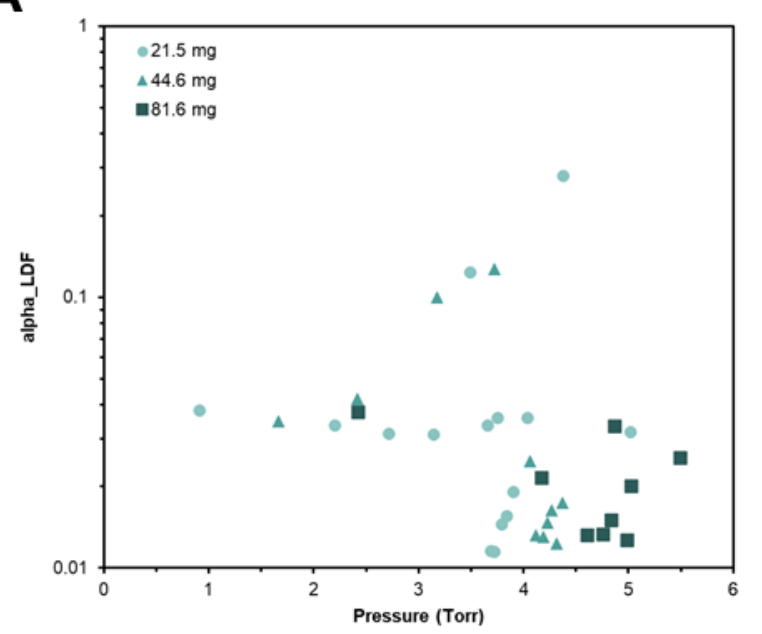

C

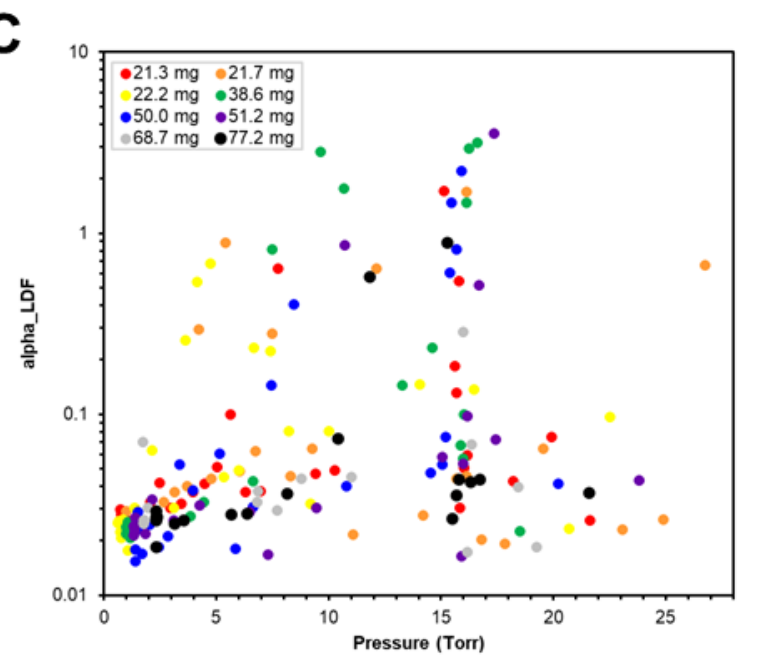

E

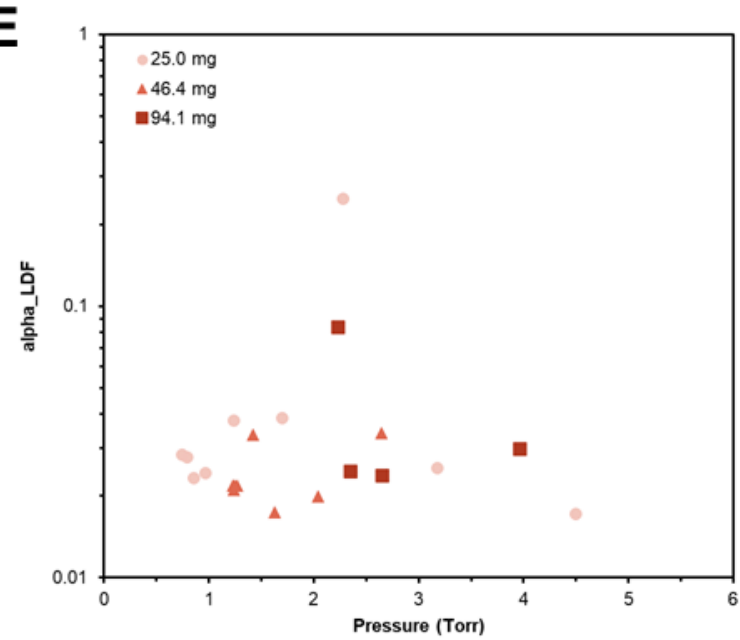

B
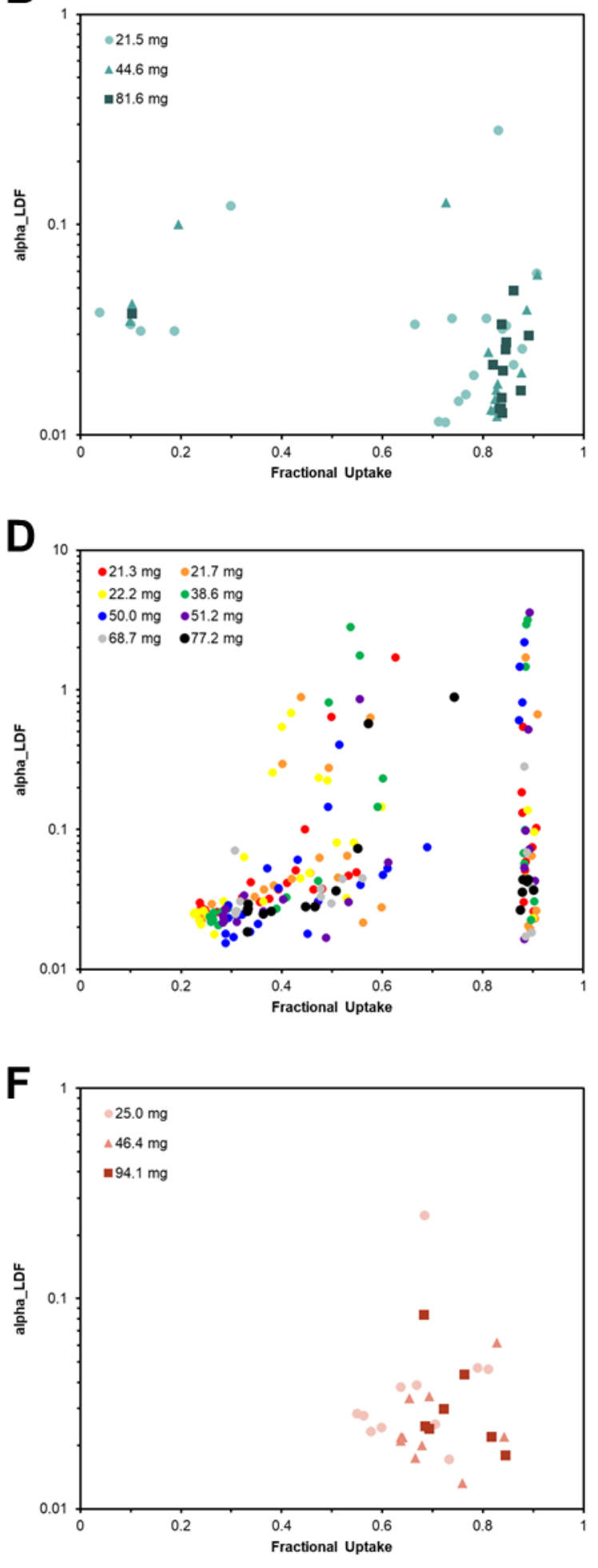

Figure S21. $\alpha_{\mathrm{LDF}}$ as a function of pressure for A) MOF-808, C) NU-1000, and E) UiO-66. $\alpha_{\mathrm{LDF}}$ as a function of pressure as a function of fractional uptake for B) MOF-808, D) NU-1000, and F) UiO-66. 
A

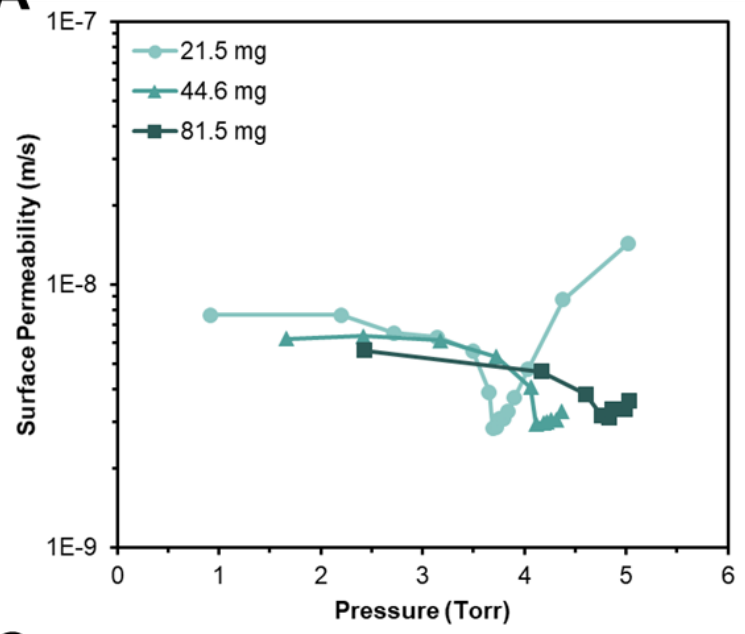

C
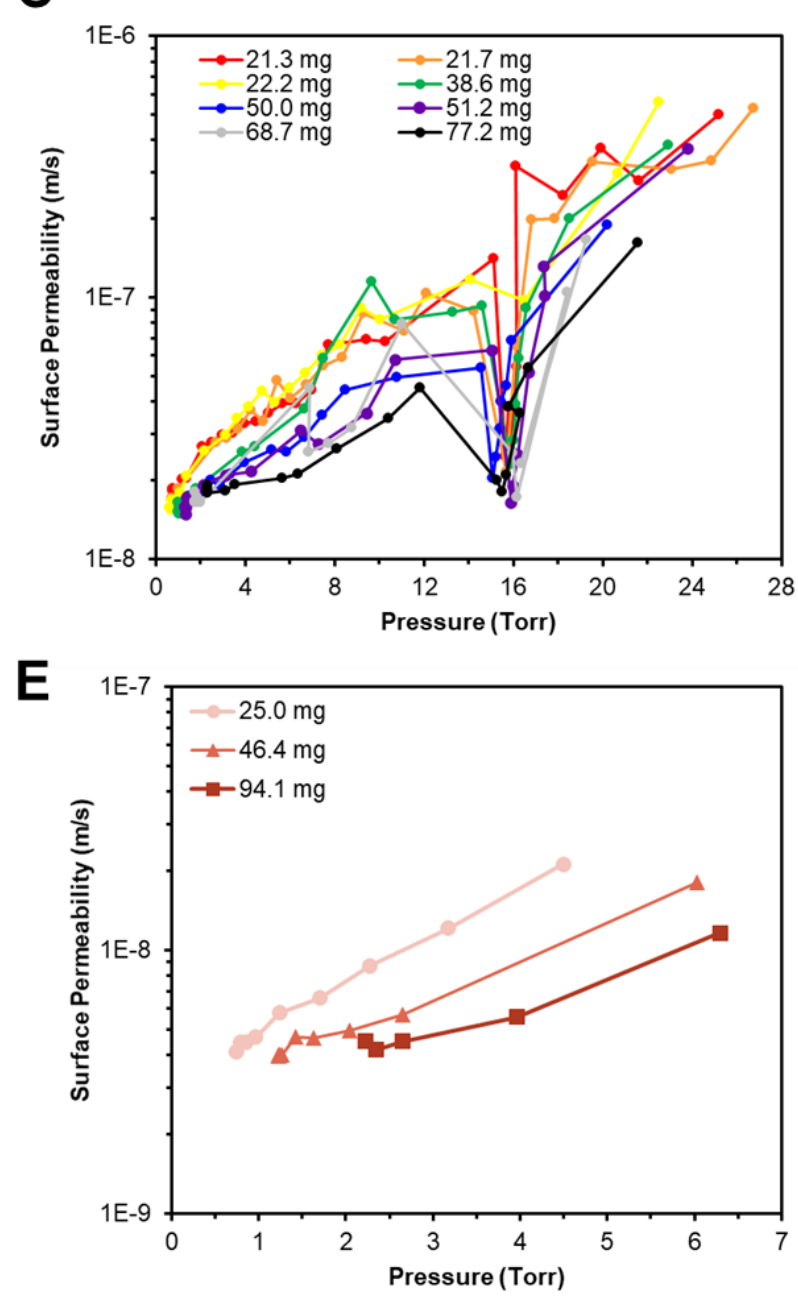

B

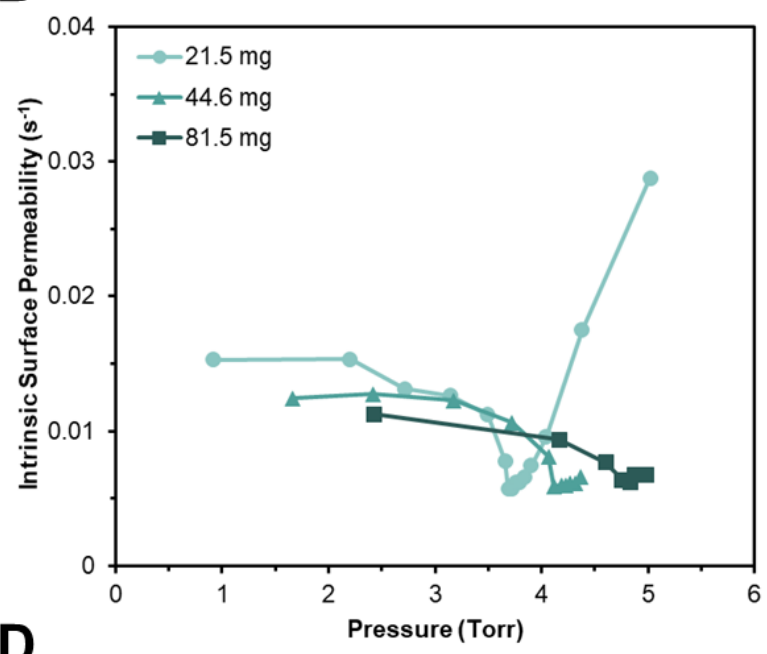

D

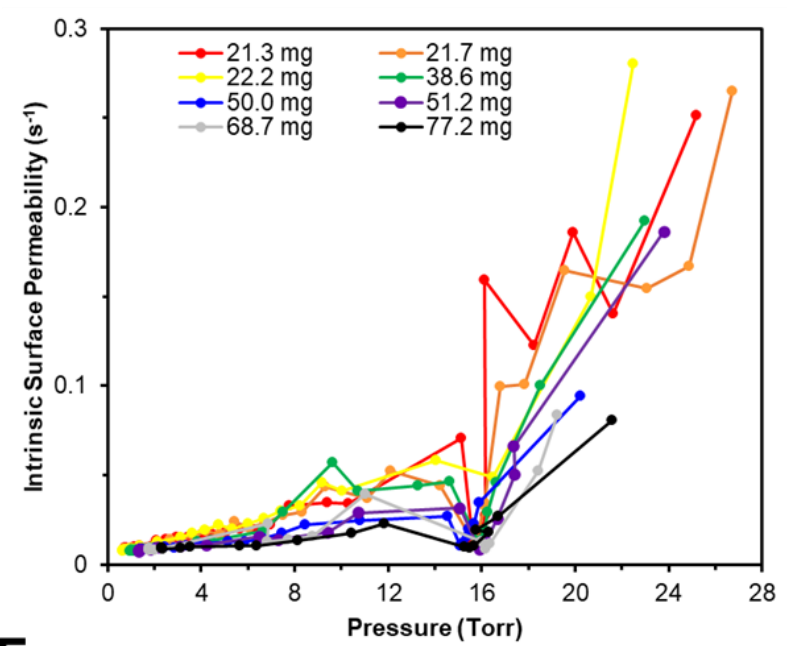

$\mathbf{F}$

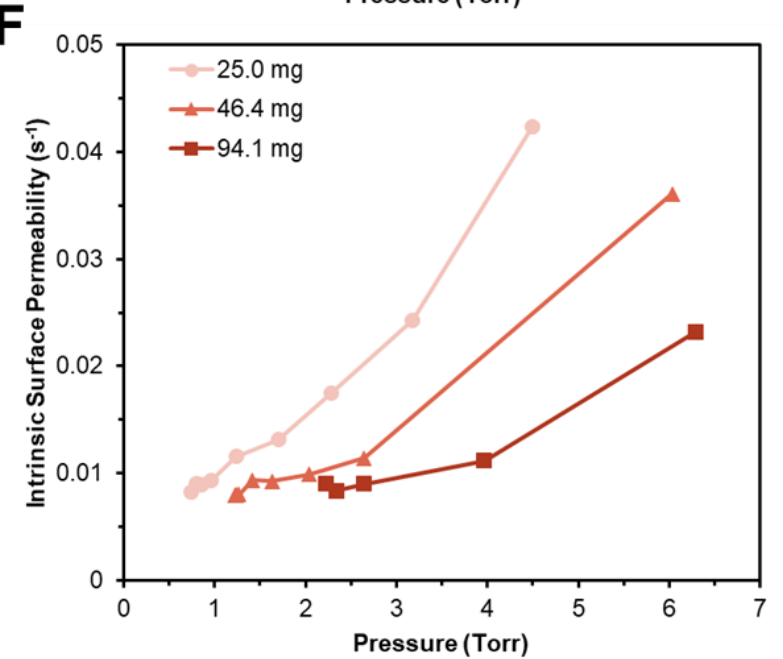

Figure S22. Surface permeability as a function of pressure for A) MOF-808, C) NU-1000, and E) UiO-66. Intrinsic surface permeability as a function of pressure for B) MOF-808, D) NU-1000, and F) UiO-66. 


\section{References}

1. Brandani, S. Analysis of the Piezometric Method for the Study of Diffusion in Microporous Solids: Isothermal Case. Adsorption 1998, 4, 17-24.

2. Brandani, S.; Brandani, F.; Mangano, E.; Pullumbi, P. Using a Volumetric Apparatus to Identify and Measure the Mass Transfer Resistance in Commercial Adsorbents. Microporous and Mesoporous Materials 2020, 304, 109277.

3. Islamoglu, T.; Otake, K.-I.; Li, P.; Buru, C. T.; Peters, A. W.; Akpinar, I.; Garibay, S. J.; Farha, O. K. Revisiting the structural homogeneity of NU-1000, a Zr-based metal-organic framework. CrystEngComm 2018, 20, 5913-5918.

4. Liu, X.; Kirlikovali, K. O.; Chen, Z.; Ma, K.; Idrees, K. B.; Cao, R.; Zhang, X.; Islamoglu, T.; Liu, Y.; Farha, O. K. Small Molecules, Big Effects: Tuning Adsorption and Catalytic Properties of Metal-Organic Frameworks. Chem. Mater. 2021, 33, 1444-1454.

5. Hanna, S. L.; Rademacher, D. X.; Hanson, D. J.; Islamoglu, T.; Olszewski, A. K.; Nenoff, T. M.; Farha, O. K. Structural Features of Zirconium-Based Metal-Organic Frameworks Affecting Radiolytic Stability. Ind. Eng. Chem. Res. 2020, 59, 7520-7526. 